\title{
Food Safety in Sub urban Market: Knowledge, Attitude and Practice of Hand Hygiene in Wadata Market, Makurdi, Benue State, Nigeria
}

\author{
Ogbeyi $\mathrm{OG}^{1^{*}}$, Afolaranmi $\mathrm{TO}^{2}$, Amede $\mathrm{PO}^{3}$, Audu $\mathrm{O}^{1}$, Koko $\mathrm{BT}^{4}$. \\ ${ }^{\prime}$ Department of Epidemiology and Community Health, College of Health Sciences, Benue State University, Makurdi, Nigeria. \\ ${ }^{2}$ Department of Community Medicine, University of Jos, Plateau State, Nigeria. \\ ${ }^{3}$ Nigerian Prison Service, Bauchi Command, Bauchi, Nigeria. \\ ${ }^{4}$ Department of Paediatrics, Federal Medical Centre, Benue State, Nigeria.
}

\begin{abstract}
A large number of males and females are engaged in the provision of food in Wadata market. Hand hygiene is the cornerstone of infection prevention (IP). When optimally performed, hand hygiene reduces healthcare-associated infections (HAI), spread and antimicrobial resistance (AMR). Poor compliance with hand hygiene practices remains a challenge for IP practitioners all over the world. More than 250 food borne diseases are caused by bacteria or parasites. This study was conducted using a descriptive cross-sectional study of 138 respondents in Wadata market. Peer reviewed and pilot tested questionnaires were employed. The questionnaires were classified into four sections namely-socio - demographic characteristics, knowledge on hand hygiene, attitude towards food hygiene and hygiene practices. Data analysis was done using Epi info a software package for statistical analysis version 23 . Majority (40.6\%) of the respondents were between the ages of 21-30 years. There were more females ( $80.6 \%)$ food vendors than males. Over $65 \%$ of the respondents had education above secondary school; and most of them obtained information on hand hygiene from mass media. Over $62 \%$ could define hand hygiene correctly while more than $90 \%$ had positive attitude towards hand hygiene. The practice level of the respondents of hand hygiene in this study was poor $42.7 \%$. There was significant association between educational status and knowledge of hand hygiene $(\mathrm{p}<0.05)$. Overall knowledge of hand hygiene of the respondents was good and they had positive attitude towards hand hygiene but this did not strictly translate to good practices of hand hygiene.
\end{abstract}

*Corresponding Author: Ogbeyi Ofikwu Gabriel. Department of Epidemiology and Community Health, College of Health Sciences, Benue State University, Makurdi, Benue State, Nigeria.Email: ogbeyiofikwu@gmail.com

Keywords: Attitude, Knowledge, Market, Nigeria, Practice, Safety

\section{INTRODUCTION}

$\mathrm{F}$ or generations, hand washing with soap and water had been considered as a measure of personal hygiene. ${ }^{1}$ Hand hygiene is a general term that applies to hand washing, antiseptic hand wash, antiseptic hand rub or surgical hand antisepsis. ${ }^{2}$ World Health Organisation (WHO) reported an overall estimate of about 1.4 million patients in developed and developing countries affected anytime by health care associated infections resulting from poor hand hygiene. ${ }^{3,4}$ Hand hygiene is the cornerstone of infection prevention and control (IPC). When optimally performed, hand hygiene reduces healthcare-associated infections (HAI) and the spread and antimicrobial resistance (AMR). ${ }^{5}$ The World Health Organization (WHO) estimated that in developed 
countries up to $30 \%$ of the population suffer from food borne diseases each year, whereas in developing countries up to 2 million deaths are estimated per year. ${ }^{6,7,8}$ Accordingly, food handlers with poor personal hygiene and lack of awareness of important issues in preventing food borne diseases, working with food industry could be potential sources of infections of many intestinal helminthes of protozoa and enterogenic pathogens. ${ }^{9,10}$ Food vendors are significant part of food sources in both developed and developing countries including Nigeria ${ }^{11}$. They contribute significantly towards ensuring food safety, especially during processing, storage, preparation or retailing of food, and its supply to consumers in times of need. Food borne diseases are on the increase throughout the world due to poor attention given to personal and food hygiene measures by both lawmakers and people in charge of food preparation, especially in developing countries like Nigeria'. A study by the joint Food and Agricultural Organization (FAO) and the World Health Organization expert committee on food safety reported that illness due to contaminated food is perhaps the most widespread health problem in the world and a major cause of reduced economic productivity. ${ }^{2}$

In Nigeria several government agencies ranging from the local governments through states to the federal government establish several agencies for the regulation of food hygiene. The National Agency for Food and Drug Administration (NAFDAC) is responsible for the regulation of food standards in Nigeria including food hygiene. ${ }^{4}$ Food safety activities in Nigeria are highly uncoordinated. The local governments periodically send out inspectors to regulate hygiene activities among the food vendors similar to the state governments. They operate using different check lists and this is a source of confusion among the different regulatory agencies. Investigations of outbreaks of food borne diseases throughout the world showed that, in nearly all instances, they are caused by failure to observe satisfactory standards in preparation, processing, cooking, storing or retailing of food. ${ }^{1,5}$ This study examined the knowledge, attitude and practice of hand hygiene among food vendors operating in Wadata Market Makurdi, Benue State, Nigeria..

\section{MATERIALS AND METHODS}

\section{Study Area}

This study was conducted in Wadata area of Makurdi metropolis. Wadata constituted the largest slum in the city and has a high population of mainly low class inhabitants. It has a population of 38,561 and with an average annual rainfall of 1,230 millimetres. This slum is located at the long coast line of River Benue towards the southern part. There is a constant inadequate water supply in the area due to poor service delivery by the state government, power failure and broken down pipes. The environment in this area is flirty because of poor refuse disposal and blocked drainages. The water table is high and there are numerous pools of stagnant water. The most common diseases that are prevalent in the area are cholera, dysentery, malaria, HIV and AIDS and motor cycle accidents popularly called 'going'. There were 1725 cases of cholera outbreaks between May 2014 and March 2015.,11

\section{Study Design}

A cross sectional descriptive study design was employed in this study.

\section{Study Population}

Makurdi metropolis has a total of five markets. Wadata market was selected by simple random sampling by balloting. The study population constituted all the food vendors operating at Wadata market. The market has an association of food vendors. They have registers where all the names of members are. The requirements for membership were medical certificate of fitness which must show results of chest $\mathrm{x}$-ray, widal test, stool and urinalysis. They were also required to pay a registration fee of fifty five thousand naira only to the market authority. The total number of food vendors in the market was 310 and the industry is open to males and females. Registered members below eighteen years were excluded from the study.

\section{Sample Size and Sampling Technique}

The sample size of this study was calculated using the formula $=\underline{z^{2}} \mathrm{pq}^{12,13}$

$$
\mathrm{d}^{2}
$$

Where:

$\mathrm{n}=$ minimum sample size for a population, $\mathrm{z}=$ standard normal deviate corresponds to 1.96 at $95 \%$ confidence interval, $\mathrm{p}=$ prevalence obtained from previous study, which was $80.0 \%$ (diseases associated with poor sanitary condition in the world in 2015) $16, \mathrm{p}=80.0 \%=0.80, \mathrm{q}=$ complementary probability, $\mathrm{q}=(1-\mathrm{P})=1-0.800=0.200, \mathrm{~d}=$ degree of accuracy and $\mathrm{d}=5 \%(0.05)$. 
Therefore: $\mathrm{n}=\underline{(1.92)^{2} \times 0.800 \times 0.200}$

$\mathrm{n}=\underline{3.842 \times 0.800 \times 0.200}$ 0.0025

$\mathrm{n}=245.9, \mathrm{n}=246$.

Considering the fact the food vendors' population is less than 10,000 and attrition rate of $10 \%$, the correction for infinite factor was made and minimum sample size was adjusted to 138.

\section{Data collection}

Data collection was made using an interviewer administered questionnaires. The information collected included sociodemographic characteristics, knowledge, attitude and practice of the respondents on food vendors hand hygiene. A pretesting of the questionnaire was carried on $14(10 \%$ of the calculated minimum sample size) in Aliade market which is thirty minutes drive from Makurdi. The studied was conducted between February and May 2019.

\section{Data Management}

Data collected were checked for completeness. All data generated were processed and analysed by EPI info version 23 an epidemiological software programme for testing proportions and calculations of means. Data were summarized and presented as frequency tables and charts. Chi-square(x2) test was used to test for statistical relationships between proper practices, attitude and knowledge of hand hygiene amongst food vendors in Wadata market.

\section{Ethical Issues}

Ethical approval for the study was obtained from the ethical committee of the Benue State University Teaching hospital Makurdi and a written approval was obtained from the management of Wadata Food Vendors Association. Informed verbal consent was obtained from each participant before the study was carried out.

\section{RESULTS}

Table 1 showed the socio-demographic characteristics of the respondents. Majority $56(40.6 \%)$ of the respondents were between the ages 21-30, 41(29.7\%) were between the ages 31-40 and less than one percent were between the ages 51-60 years. More than three-quarters of the respondents $(80.6 \%)$ were female food vendors. The study also revealed that majority of the respondents (65.6\%) had secondary school education as the highest educational qualification while $23.9 \%$ had primary school education and only $8.9 \%$ had tertiary education. The rest (1.6\%), had no formal education. Most of the respondents were traders (78.5\%), farmers $(1.7 \%)$ and civil servants $(2.4 \%)$. The ethnic distribution of the respondents also showed that the major tribes were Tivs and Idomas.

Table 1: Socio-demographic characteristics of the respondents

\begin{tabular}{|c|c|c|}
\hline Variable & Frequency & Percent \\
\hline \multicolumn{3}{|c|}{ Age groups of Respondents } \\
\hline$\geq 20$ & 20 & 14.5 \\
\hline $21-30$ & 56 & 40.6 \\
\hline $31-40$ & 41 & 29.7 \\
\hline $41-50$ & 19 & 13.8 \\
\hline $51-60$ & 2 & 0.8 \\
\hline \multicolumn{3}{|c|}{ Sex distribution of Respondents } \\
\hline Male & 23 & 16.7 \\
\hline Female & 115 & 83.3 \\
\hline \multicolumn{3}{|c|}{ Highest level of education attained } \\
\hline No formal education & 3 & 2.2 \\
\hline Primary school education & 31 & 22.5 \\
\hline Secondary educatio & 91 & 65.9 \\
\hline Tertiary education & 13 & 9.4 \\
\hline \multicolumn{3}{|c|}{ Occupation of Respondents } \\
\hline Trading & 115 & 83.3 \\
\hline Farming & 13 & 9.4 \\
\hline Civil servant & 4 & 2.9 \\
\hline Student & 3 & 2.2 \\
\hline Housewife & 3 & 2.2 \\
\hline \multicolumn{3}{|c|}{ Tribe distribution of Respondents } \\
\hline Tiv & 82 & 59.4 \\
\hline Idoma & 26 & 18.8 \\
\hline Igede & 6 & 4.3 \\
\hline Others & 24 & 17.5 \\
\hline
\end{tabular}




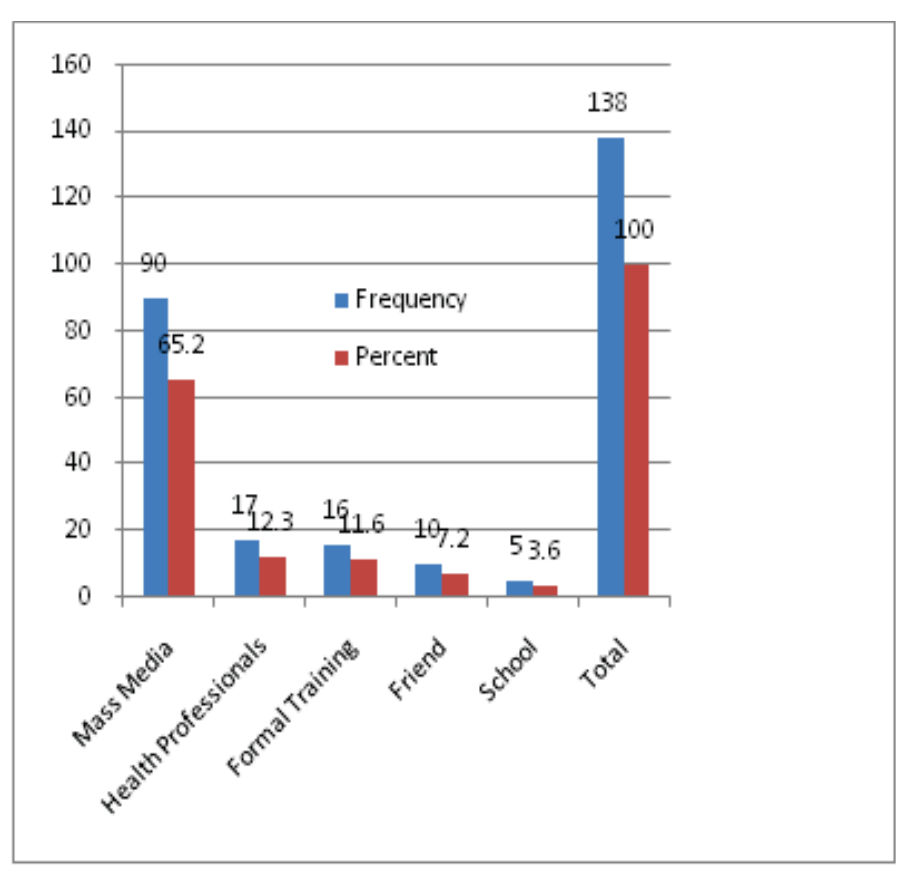

Fig 1 sources of information of the respondents.

Fig 1 showed that majority of the respondents $65.2 \%$ got the information on hand hygiene from mass media, $12.3 \%$ from health professionals, training $(11.6 \%)$, friends $(7.2 \%)$ and $\operatorname{school}(3.6 \%)$.

Table 2 showed the knowledge of respondents on hand hygiene. Majority of them (62.3\%) defined hand hygiene correctly as washing of hands with the use of antiseptic and water, followed closely by $35.5 \%$ who opined that hand hygiene is "hand washing with water only" while $(0.7 \%)$ said "cooking before washing of hands" was hand hygiene and $1.4 \%$ submitted that hand hygiene was "handling of food without washing of hands".

Almost half (46.4\%) of the respondents defined improper hygiene to be "not washing of hands after the use of toilet", while $29.0 \%$ respondents opined that improper hand hygiene meant "keeping of long nails while handling food", $2.2 \%$ of the respondents opined that improper hand hygiene was "the use of hand ornaments while cooking", and $18.1 \%$ respondents submitted that improper hand hygiene meant "not washing of hands before cooking" and 4.3\% respondents were of the opinion that improper hand hygiene was "serving food with open hand injuries". The results also showed that majority $(76.8 \%)$ of the respondents had knowledge of diseases that may be associated with improper hand hygiene.
Table 2: Knowledge on hand hygiene among the respondents

\begin{tabular}{|c|c|c|}
\hline Variables & Frequency & Percent \\
\hline \multicolumn{3}{|l|}{ Awareness of hand hygiene } \\
\hline Yes & 134 & 97.1 \\
\hline No & 4 & 2.9 \\
\hline \multicolumn{3}{|l|}{ Hand hygiene is: } \\
\hline Hand washing with water only & 49 & 35.5 \\
\hline Washing hands with antiseptic and water & 86 & 62.3 \\
\hline Coo king before washing hands & 1 & 0.7 \\
\hline Handling of food without washing hands & 2 & 1.4 \\
\hline \multicolumn{3}{|l|}{ What is improper hand hygiene? } \\
\hline Keeping long nails while handling food & 40 & 29.0 \\
\hline Not washing hands after use of toilet & 64 & 46.4 \\
\hline Use of hand ornaments while cooking & 3 & 2.2 \\
\hline Not washing of hands before cooking & 25 & 18.1 \\
\hline Serving food with open hand wounds & 6 & 4.3 \\
\hline \multicolumn{3}{|l|}{ Are you aware of diseases associated with } \\
\hline \multicolumn{3}{|l|}{ poor hand hygiene } \\
\hline Yes & 106 & 76.8 \\
\hline No & 32 & 23.2 \\
\hline \multicolumn{3}{|l|}{ List of diseases identified by respondents to } \\
\hline \multicolumn{3}{|l|}{ be associated with poor hand hygiene } \\
\hline Diarrhoea & 41 & 29.7 \\
\hline Typhoid & 26 & 18.8 \\
\hline Cholera & 15 & 10.9 \\
\hline Dysentery & 5 & 3.6 \\
\hline Fever & 4 & 2.9 \\
\hline Food poisoning & 2 & 1.4 \\
\hline Malaria & 3 & 2.1 \\
\hline Vomiting & 2 & 1.4 \\
\hline Stomach pain & 1 & 0.7 \\
\hline Don’t know & 39 & 28.3 \\
\hline \multicolumn{3}{|l|}{ Respondents knowledge of methods of disease } \\
\hline \multicolumn{3}{|l|}{ prevention while handling food } \\
\hline W ashing hands before serving & 31 & 22.5 \\
\hline Washing hands after defecation & 84 & \\
\hline Regular trimming of nails & 8 & 5.8 \\
\hline Avoid handling of food with open hand wounds & 14 & 10.1 \\
\hline Proper hand washing after scratching of the body & 1 & 0.7 \\
\hline \multicolumn{3}{|l|}{ Have you been trained on hand hagge } \\
\hline Yes & 25 & 18.1 \\
\hline No & 113 & 81.800 .9 \\
\hline
\end{tabular}


Table 3: Attitude of respondents towards hand hygiene

\begin{tabular}{|c|c|c|}
\hline Variable & Frequency & Percent \\
\hline \multicolumn{3}{|c|}{ Respondents belief on wearing } \\
\hline \multicolumn{3}{|c|}{ protective covering while handling food } \\
\hline Yes & 119 & 86.2 \\
\hline No & 19 & 13.8 \\
\hline \multicolumn{3}{|c|}{ Respondents belief on Washing hands } \\
\hline \multicolumn{3}{|c|}{ before handling food } \\
\hline Yes & 3 & 97.8 \\
\hline $\mathrm{N} o$ & 135 & 2.2 \\
\hline \multicolumn{3}{|c|}{ On whether persons with cuts in the } \\
\hline \multicolumn{3}{|c|}{ hands should not handle food } \\
\hline Yes & 135 & 97.8 \\
\hline No & 3 & 2.2 \\
\hline \multicolumn{3}{|c|}{ On washing of hands with soap and } \\
\hline \multicolumn{3}{|l|}{ water } \\
\hline \multicolumn{3}{|c|}{ after using the toilet } \\
\hline Yes & 134 & 97.1 \\
\hline No & 4 & 2.9 \\
\hline \multicolumn{3}{|c|}{ On whether the towel used to clean food } \\
\hline \multicolumn{3}{|c|}{ surfaces should be used to clean hands } \\
\hline Yes & 5 & 3.6 \\
\hline No & 133 & 96.4 \\
\hline \multicolumn{3}{|c|}{ On whether food handlers should keep } \\
\hline \multicolumn{3}{|l|}{ long nails } \\
\hline Yes & 136 & 98.6 \\
\hline No & 2 & 1.4 \\
\hline \multicolumn{3}{|c|}{ On whether food handlers should wear } \\
\hline \multicolumn{3}{|c|}{ hand ornaments } \\
\hline Yes & 129 & 93.5 \\
\hline No & 9 & 6.5 \\
\hline \multicolumn{3}{|c|}{ On whether food handlers believe nose } \\
\hline \multicolumn{3}{|c|}{ picking can transmit germs } \\
\hline Yes & 134 & 97.1 \\
\hline No & 4 & 2.9 \\
\hline
\end{tabular}

Table 3 showed that majority of the respondents119 (86.2\%) believed wearing protective covering could reduce the risk of food contamination. Almost all $(97.8 \%)$ respondents agreed that food vendors should wash their hands before handling food. Most of them (97.8\%) also agreed that persons with cuts on the hand should not handle food. A vast majority of the respondents (97.1\%) also agreed that food vendors should wash their hands after using the toilet. Most (96.4\%) of them disagreed that the towel used to clean food surfaces should be used to clean hands. Almost all $(98.6 \%)$ believed food handlers should keep long nails. Majority (93.5\%) also believed food handlers should wear hand ornaments. Almost all (97.1\%) believed nose picking could transmit germs.

Table 4: Practice of hand hygiene among Respondents

\begin{tabular}{|c|c|c|}
\hline Variable & Frequency & Percent \\
\hline \multicolumn{3}{|c|}{ On how often respondents cut their nails } \\
\hline Always & 52 & 37.7 \\
\hline Occasionally & 86 & 62.3 \\
\hline Total & 138 & 100 \\
\hline \multicolumn{3}{|c|}{$\begin{array}{l}\text { On how often respondents wash their } \\
\text { hands with soap and water }\end{array}$} \\
\hline Always & 79 & 57.2 \\
\hline Occasionally & 58 & 42.0 \\
\hline Not at all & 1 & 0.7 \\
\hline Total & 138 & 100 \\
\hline \multicolumn{3}{|c|}{$\begin{array}{l}\text { On how often respondents use antiseptic } \\
\text { hand wash }\end{array}$} \\
\hline Always & 31 & 22.5 \\
\hline Occasionally & 80 & 58.0 \\
\hline Not at all & 27 & 19.6 \\
\hline Total & 138 & 100 \\
\hline \multicolumn{3}{|c|}{$\begin{array}{l}\text { On how often respondents use tidy } \\
\text { clothes for cleaning }\end{array}$} \\
\hline Always & 85 & 61.6 \\
\hline Occasionally & 50 & 36.2 \\
\hline Not at all & 3 & 2.2 \\
\hline Total & 138 & 100 \\
\hline \multicolumn{3}{|c|}{$\begin{array}{l}\text { On how often respondents take their } \\
\text { bath }\end{array}$} \\
\hline Always & 97 & 70.3 \\
\hline Occasionally & 41 & 29.7 \\
\hline Total & 138 & 100 \\
\hline \multicolumn{3}{|c|}{$\begin{array}{l}\text { On how often respondents take their } \\
\text { bath }\end{array}$} \\
\hline Always & 97 & 70.3 \\
\hline Occasionally & 41 & 29.7 \\
\hline Total & 138 & 100 \\
\hline \multicolumn{3}{|c|}{$\begin{array}{l}\text { On how many times respondents clean } \\
\text { their working area per day }\end{array}$} \\
\hline Only once & 11 & 8.0 \\
\hline Twice only & 23 & 16.7 \\
\hline Once it is dirty & 104 & 75.4 \\
\hline Total & 138 & 100 \\
\hline \multicolumn{3}{|c|}{$\begin{array}{l}\text { On respondents that wash hands always } \\
\text { before handling food }\end{array}$} \\
\hline Yes & 135 & 97.8 \\
\hline No & 3 & 2.2 \\
\hline Total & 138 & 100 \\
\hline \multicolumn{3}{|c|}{$\begin{array}{l}\text { Of respondents with functional tap water } \\
\text { for washing hands }\end{array}$} \\
\hline Yes & 6 & 4.3 \\
\hline No & 132 & 95.7 \\
\hline Total & 138 & 100 \\
\hline
\end{tabular}


Diarrhoea was the most identified disease (29.7\%) associated with poor hand hygiene, typhoid $(18.8 \%)$, cholera $(10.9 \%)$, dysentery (3.6\%) while malaria was $(2.1 \%)$. Over $28 \%$ could not mention any disease associated with poor hand hygiene. Most $(60.9 \%)$ of the respondents agreed that washing hands after defecation can prevent disease transmission, while $22.5 \%$ believed that washing hands before serving food is important for the prevention of food borne disease transmission and $10.1 \%$ believed people with open wounds on their hands should not handle food. The study also revealed that majority $(81.9 \%)$ had no formal training on hand hygiene. Table 4 showed the practice of hand hygiene in Wadata market. In this study majority of the respondents $(62.3 \%)$ cut their nails occasionally. Slightly over $57 \%$ of the respondents affirmed to washing their hands with soap and water always, while $(42.0 \%)$ washed their hands occasionally, and $(0.7 \%)$ did not wash their hand with soap and water at all. The study also revealed that more than half $(58.0 \%)$ of the respondents occasionally used antiseptic hand wash and water, $22.5 \%$ used antiseptic hand wash always and $19.6 \%$ did not use at all. The study also showed that the respondents predominantly $85(61.6 \%)$ always used tidy clothes for cleaning, followed by $50(36.2 \%)$ who use tidy clothes occasionally for cleaning while 3 respondents $(2.2 \%)$ did not use tidy clothes for cleaning at all. Regarding personal hygiene, most of the respondents (70.3\%) took their bath always, whereas $29.7 \%$ took their bath occasionally. Concerning sanitary practices at the work place, 11 respondents $(8.0 \%)$ cleaned their working area once only, 23 respondents $(16.7 \%)$ cleaned their working area twice only and the vast majority $(75.4 \%)$ cleaned their working area once it is dirty. Almost all (97.8\%) the respondents washed their hands before handling food. However, majority $(95.7 \%)$ of the respondents did not have a functional tap for hand washing hands.

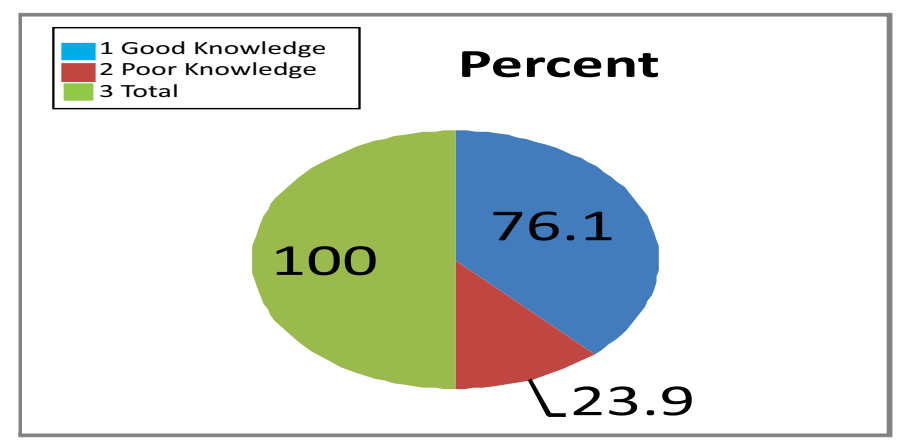

Fig 2 Respondents knowledge score
Table 5: Cross Tabulation of Educational Status and Knowledge of hand hygiene among Respondents/practice of hand hygiene and knowledge of hand hygiene.

\begin{tabular}{llcll}
\hline Variable & Chi square & Df & P value & Significance $\mathbf{p}<0.05$ \\
\hline Knowledge $\infty$ Education & 8.633 & 1 & 0.001 & Yes \\
Knowledge $\infty$ Practice & 3.081 & 1 & 0.100 & No \\
\hline
\end{tabular}

The relationship between educational status of the respondents and knowledge of hand hygiene was found to be statistically significant a $\mathrm{p}$ value 0.001 . The relationship between knowledge and practice of hand hygiene was not statistically significant at a p value 0.100

\section{DISCUSSION}

This study assessed the knowledge, attitude and practice of hand hygiene among food vendors in Benue State Nigeria. Majority of the respondents were aged 21-30 years. This is similar to some studies from other parts of Nigeria. ${ }^{14,33}$ The greatest number of those in the food vending business in the country are young adults. ${ }^{9,14}$ There were more female food vendors than males. Food vending in most Nigerian small markets are on a small scale employing less than ten persons per stall. Females have comparative advantage over males in Nigeria's restaurant industry because of the culture of the people which believed that cooking is almost an exclusive area for females. ${ }^{14}{ }^{15}$ This may be due to the fact that food vending is one of the few readily accessible avenues of employment open to women and it has low cost of entry and does not require high level of formal education. ${ }^{15,19}$ The near $10 \%$ of the respondents with tertiary education involved in food vending can be attributed to lack of job opportunities in most developing countries. High unemployment rate reduces discrimination in terms of jobs available for the various communities. ${ }^{16}$ Majority of the vendors are from the immediate environment the Tiv population. This is related to the fact that majority of the population of the people in the market are from the local area. People tend to patronize foods that are close to their cultural practices. ${ }^{15,17}$

Overall the knowledge of the respondents in this study is good with regard to food hand hygiene. This compared favourably with other studies done in some zones in Nigeria. ${ }^{14,16}$ This findings contradicted studies done in East Africa and South East Asia were majority of the respondents 
had poor knowledge of food hygiene. ${ }^{8,17}$ Almost all the food vendors were aware of hand hygiene and more than half heard about it from mass media. The awareness of such important hygienic procedures by majority of the respondents in this study is very important in disease control in the food chain. It has been shown that food vendors with poor personal hygiene, their hands can serve as vehicles for disease transmission. ${ }^{14,18}$ This is particularly important in under-five children that are prone to diarrhoeal diseases. Studies have shown that diarrhoeal diseases are significantly reduced by proper hand washing. ${ }^{18,19}$ Despite food handlers claiming that they wash their hands in the course of their duty staphylococci organisms have been isolated from their hands during epidemiological studies. ${ }^{7}$ The good knowledge score demonstrated in this study may be explained away by the high level of literacy exhibited by the respondents. Only slightly below $2 \%$ did not attend any level of education. It has been shown that education brings awareness in people and keeps them away from superstitious beliefs. Literacy level depends on education. Education promotes knowledge and understanding. Studies done in other countries showed that education had a positive correlation with knowledge. ${ }^{14,16}$

In this study, over $90 \%$ of the respondents had positive attitude towards food hand hygiene. This is important in disease reduction and control strategy in any community. Attitude has both positive and negative relationship with knowledge and education. Some studies done showed that communities with higher level of education have better attitude towards disease control and reduction. ${ }^{19}$ The negative attitude shown by the respondents in respect of keeping long finger nails and wearing hand ornaments during food preparation is worrisome. These will introduce complications or failure in disease control amongst the food vendors. Transmissions of diseases through faeco- oral routes are greatly enhanced through keeping long finger nails and wearing of hand ornaments during preparation of foods..$^{19,20}$ Food vending in Wadata market is dominated by females. Most women will do everything to look beautify all the time and that may be the reason for keeping these long finger nails and hand ornaments. ${ }^{19,14,21}$ It was however observed that despite good attitude of most food vendors towards hand hygiene, about $13.8 \%$ did not believe that wearing protective covering while handling food was important in preventing food contamination. There is therefore need for training for these respondents since only $18 \%$ had formal training in proper hygiene in food vending. These compared favourably with some work done in Vietnam and India. ${ }^{19,22}$

Practices are defined as ways in which people demonstrate their knowledge and attitude through their actions. The practice level of the respondents of hand hygiene in this study is poor $(42.7 \%)$. This is far less than the practice levels obtained in some studies in Nigeria and Ghana. ${ }^{14,16}$ This is surprising because of the good knowledge and highly positive attitude shown in this work. The literacy level in this work is also high. Some studies have shown that high level of education and good knowledge promote good practices. ${ }^{12}$ How ever few studies showed that $63 \%$ of food handlers with good knowledge in food safety did not demonstrate corresponding positive behaviour to food safety and hygiene practices. There is however significant association between practice and knowledge. ${ }^{1,23}$ It has been suggested that other factors such as employee motivation and continuous education and training on the job should be provided to inspire food-handlers, which will affect attitudes and subsequently food-safety practices. ${ }^{19}$ In this study, there is no significant association between practice and knowledge ( $p>$ 0.05). This contradicts some studies done in Vietnam, Ghana, and Nigeria and is surprising because of the high level of education among the respondents. . $^{14,16,19}$

\section{CONCLUSION}

Food vendors' knowledge of hand hygiene was good despite low level of formal training. Their attitude was generally good. Despite good knowledge and good attitude towards hand hygiene, this did not necessarily translate to a good practice of hand hygiene. The significant relationship between education and knowledge should be exploited by the various governments to institute health education programmes that will increase the level of training amongst the respondents.

\section{Recommendation}

With rapidly increasing number of food vendors especially in urban areas due to enormous population increase, there is need for more attention in the hand and food hygiene. Governments should have in place coordinated, effective, integrated and preventive strategies that emphasize vendor registration, formal training on hand hygiene practices, initial medical and periodic medical certification as well as regular 
personal and environmental hygiene checks. Food vendors should be encouraged to put more effort in proper hand hygiene by frequent hand washing before handling food, use of hand washes and gloves and proper treatment of cuts on hands. Portable running water should be made available as hand hygiene is properly practiced if there is provision of adequate water supply. Also, health education on proper hand hygiene practices and dangers of improper hand hygiene should be on all media platforms (bill boards, newspapers, television, radio, and internet) in different languages for better understanding. Regular monitoring by appropriate agencies should be put in place by governments in conjunction with food vendor's union.

\section{Conflict of Interest}

None declared.

\section{REFERENCES}

1. Rotter, M. Hand washing and hand disinfection. Philadelphia:Lippincott Williams \& Wilkins, 2011; pp. 13391355.

2. Larsen E L. APIC Guidelines Committee. APIC Guideline for hand washing and hand antisepsis in health care settings. American Journal for Infection Control; 2012; Pp 23:251-69.

3. World Alliance for patient safety. The Global patient safety challenge 2010-2014 "Clean Care is Safer Care" Geneva World Health Organization 2015; Available from: http://www.who.int/gpsc/en/. (Accessed on 04/2/2019)

4. Mathur P. Hand hygiene: Back to the basics of infection control. Indian Journal of Medical Research, 2011; 134: 611-620.

5. Pires D, Bellissimo-Rodrigues F and Pittet D. The evolution in Hand Hygiene literature. In: Hand Hygiene: A Handbook for Medical Professionals. Oxford: Wiley-Blackwell, 2017; 391-399.

6. Kubde S R, Pattankar J and Kokiwar P R, Knowledge and food hygiene practices among food handlers in food establishments. International Journal of Community Medicine and Public Health, 2016; 3(1):251-256.

7. Park K. Nutrition and Health. In: Park's Text Book of Preventive and Social Medicine, 21st ed. Jabalpur: Banarasidas Bhanot publishers, 2011; p.607.

8. Abera B, Biadegelgen F and Bezabih B. Prevalence of Salmonella typhi and intestinal parasites among food handlers in Bahir Dar Town, Northwest Ethiopia. Ethiopian Journal of Health Development, 2010; 24(1):46-50.

9. Takalkar A A and K umavat A P. Assessment of personal hygiene of canteen workers of Government Medical College and Hospital, Solapur. National Journal of Community Medicine, 2011; 2(3):448-51.

10. Nigusse D and Kumie A. Food hygiene practices and prevalence of intestinal parasites among food handlers working in Mekelle
University student's cafeteria, Mekelle. Global Advanced Research Journal of Social Science, 2012; 1(4):65-71.

11. Lawan U M., Iliyasu Z, Abubakar S and Gajida A U, Abdussalam A. Personal and food hygiene practices of subsistence food vendors operating in Kano metropolis, Northwestern Nigeria. International Journal of Medical Science and Public Health, 2015; 4 (2): 214-221.

12. Araoye M. O. Research methodology for health and social science. Illorin Nigeria. $1^{\text {st }}$ Edition. Nathadex publishers, 2003; 118-121.

13. Annor G A and Baiden E A. Evaluation of food hygiene knowledge, attitudes and practices of food handlers in food businesses in Accra, Ghana. Food and nutrition, 2011; 2:830836.

14. Aluh F O, and Aluh D O. Knowledge, attitudes and practices of food hygiene among mobile food vendors in a Nigerian rural settlement. International Journal of Community Medicine and Public Health, 2017; 4(11):4025-403015

15. Federal Ministry of Water Resources National Water Supply and Sanitation. Sixth Edition, 2015.

16. Fortune A E H. Food safety knowledge, attitudes and practices of institutional food-handlers in Ghana. BMC Public Health 2017; 17(40): 101-112

17. Mudey A B, Kesharwani N, Mudey G A, Goyal R C, Dawale A and Wagh V. Health status and personal hygiene among food handlers working at food establishment around a rural teaching hospital in Wardha district of Maharashtra, India. Global Journal of Health Sciences, 2010; 2(2):198-204.

18. Woh P Y, Thong K L, Behnke J M, Lewis J W and Zain S N M. Characterization of Nontyphoidal Salmonella Isolates from Asymptomatic Migrant Food Handlers in Peninsular Malaysia. Journal of Food Protection. 2017;80(8):1378-1383 CrossRef

19. Luu P H, Davies B, and Dunne M P. The association between factors which affect the food safety practices of sea food distributors within the southern domestic distribution chains in Vietnam. Food Control.2017;73:332-340 $\underline{\text { CrossRef }}$

20. Stepanović S, Dakić I, Morrison D, Hauschild T, Ježek P, Petráš P, Martel A, Vuković D, Shittu A, and Devriese LA. Identification and characterization of clinical isolates of members of the Staphylococcus sciuri group. J Clin Microbiol. 2005;43(2):956-8.

21. Deyan S, Olumide A O, Alexander P, Ralica K, Foad F, and Bamidele F.A. Food safety knowledge and hygiene practices among veterinary medicine students at Trakia University, Bulgaria. Journal of Infection and Public Health, 2016; 10 (2017) 778-782. Accessed from http:// www.elsevier.com/locate/jiph. Date assessed 17-6-2019.

22. Mohd FS, Son R, Mohhiddin O, Tot P S and Chai LC. Food court hygiene assessment and food safety knowledge, attitudes and practices of food handlers in putrajaya. International food research journal, 2015; 22(5); 1843-1854.

23. Clayton DA, Griffith CJ, Price P, Peters AC. Food handlers' beliefs and self-reported practices. Int J Environ Health Res. 2002;12(1):25-39. 


\title{
Assessing the Clinical Utility of Haptoglobin to Creatinine Ratio as a Test for Detecting Nephropathy among Type 2 Diabetic Patients
}

\author{
Mohammed $\mathrm{IY}^{1 *}$, Busari $\mathrm{AO}^{2}, \mathrm{Ahmad}_{\mathrm{MB}}{ }^{2}$ \\ ${ }^{I}$ Department Chemical pathology, and ${ }^{2}$ Department of Medical Laboratory Science, Bayero University Kano, Kano \\ *Corresponding Author: Mohammed Idris Yahaya. Department Chemical pathology, Bayero \\ UniversityKano,Email:1idrismoore@gmail.coma.
}

\begin{abstract}
Diabetic nephropathy is the leading cause of diabetic complications and end stage renal disease worldwide, especially in Nigeria. This study assessed the clinical utility of urine Albumin to Creatinine ratio (UACR) and urine Haptoglobin to Creatinine ratio (UHCR) in detecting nephropathy among type 2 diabetic patients attending Aminu Kano Teaching Hospital. Eighty (80) type 2 diabetic patients attending Aminu Kano Teaching Hospital were recruited for this study after excluding those with overt proteinuria. Blood sample was collected for quantitative determination of serum creatinine using Jaffe's method while the Urine sample was received for quantitative determination of urine albumin and urine haptoglobin levels. Linear regression model revealed a unit change in urine albumin to creatinine ratio (UACR) and urine haptoglobin to creatinine ratio (UHCR) with a significant reduction in estimated Glomerular Filtration Rate (eGFR) by $2.197 \mathrm{ml} / \mathrm{min}$ and $27.969 \mathrm{ml} / \mathrm{min}$ respectively $(\mathrm{p}<0.05)$ when used while logistic regression model demonstrated that UHCR have $91.7 \%$ sensitivity, $95 \%$ specificity, $98 \%$ positive predictive value and $79 \%$ negative predictive compared to UACR with $83.3 \%$ sensitivity, $75 \%$ specificity, $91 \%$ positive predictive and $60 \%$ negative predictive. Based on these findings, UHCR is a good marker for detecting nephropathy in diabetic patients.
\end{abstract}

Keywords: Diabetic Nephropathy, Urine albumin,Urine Haptoglobin

\section{INTRODUCTION}

$\mathrm{S}_{\mathrm{c}}^{\mathrm{i}}$ ckle Diabetic nephropathy is a microvascular complication of diabetes mellitus and the leading cause of end stage renal disease worldwide. ${ }^{1}$ It is a clinical syndrome characterized by persistent albuminuria, a relentless decline in glomerular filtration rate (GFR), raised arterial blood pressure and relative increased mortality from cardiovascular diseases. ${ }^{2}$

In Nigeria, prevalence rate of diabetes mellitus was estimated to be $5.0 \%$, with $3.0 \%$ prevalence in Northwest Nigeria and $5.5 \%$ prevalence in Southwest Nigeria. ${ }^{4}$ Reports from seven tertiary hospitals in Nigeria show that $3.2 \%$ of diabetic complication accounts for diabetic nephropathy. ${ }^{5}$ Microalbuminura has been the hallmark diagnostic biomarker for early detection of diabetic nephropathy and assessing its associated condition. ${ }^{6}$ Microalbuminuria is defined as urinary albumin excretion between 30 and $300 \mathrm{mg} / 24 \mathrm{hrs}$ or 20 $200 \mu \mathrm{g} / \mathrm{min}$ for timed urine collection. ${ }^{7}$ Though, the 
appropriate sample for microalbumin estimation is 24 hours urine sample but due to the difficulties and errors that may occur during the collection, albumin/creatinine ratio (UACR) in early morning spot urine was adopted as a diagnostic alternative to correct for limitations. ${ }^{8}$ However, studies have shown that urinary albumin to creatinine ratio is neither sensitive nor specific for early detection of diabetic nephropathy. ${ }^{9,10}$ Studies have also shown that many patients who have microalbuminuria at one point in time might not have it when measured later and as such makes it a poor predictor of the development of macroalbuminuria. ${ }^{11}$

Studies on diabetic induced transgenic mice also showed that haptoglobin is a major determinant of the development and progression of diabetic renal disease. ${ }^{12}$ In a recent study, urinary haptoglobin was reported to predicts renal progression independent of albuminuria and also improve the predictive performance of albuminuria beyond traditional risk factors in Asians with type 2 diabetes mellitus. ${ }^{10}$ Haptoglobin is an alpha-2 sialo glycoprotein that is synthesized in the liver but other tissues including kidney have been shown to express it. ${ }^{13}$ The early detection of diabetic nephropathy is of paramount importance to provide appropriate therapy that will prevent evolution to end stage renal disease most especially among low and middle income countries like Nigeria where facilities to cater for such patient may be prohibitive interms of availability and cost. In this regard, haptoglobin has recently been identified as a predictor of early renal injury before the manifestation of chronic kidney disease and end stage renal disease. Such a predictor, if available for early detection of renal injury may permits targeted treatment with more aggressive therapies at earlier stage that will prevent deterioration in kidney function. This study therefore aimed to assess the diagnostic utility of urinary haptoglobin/creatinine (UHCR) ratio for detecting diabetic nephropathy.

\section{MATERIALS AND METHODS}

This cross-sectional study was conducted between July 2018 to July 2019 among Type 2 diabetic patients attending Aminu Kano Teaching Hospital for follow up treatment. Kano State is located at $11^{\circ} 30^{\prime} \mathrm{N} 8^{\circ} 30^{\prime} \mathrm{E}$ in the Northern Nigeria. It was created on May 27, 1967 and bordered by Katsina State to the north-west, Jigawa State to the north-east, Bauchi State to the south-east and Kaduna State to the south-west. The capital of
Kano State is Kano. It has a total Area of $20,131 \mathrm{Km}^{2}$ with an estimated population of $11,058,300$ and density of $470 / \mathrm{Km}^{2}$. An estimated sample size of 80 was made based on the prevalence rate of diabetes in Nigeria using the formula proposed by Susan et al., 2015. ${ }^{14}$ Recruitment was by systematic random sampling after obtaining an informed consent from the study subjects. Subjects presenting with the following conditions were excluded from the study: insulin therapy, pregnancy, cardiovascular disease, urinary tract infection, menstruation and cigarette smoking. A structured pretested questionnaire was used to obtain relevant disease and treatment history. Ethical approval was sought from the institutional research committee reference number NHREC/ $21 / 08 / 2008 /$ AKTH/EC/ 2252 and $\mathrm{AKTH} / \mathrm{MAC} / \mathrm{SUB} / 12 \mathrm{~A} / \mathrm{P}-3 / \mathrm{VI} / 2352$. Urine and Blood samples were collected from all recruited participants.

\section{Statistical analysis}

Data analysis was done using Statistical Package for Social Sciences (SPSS) version 16.0 Software. The measured values for urinary albumin, haptoglobin and creatinine concentrations were presented as mean \pm standard deviation. UACR and UHCR were calculated by dividing the urine albumin and urine haptoglobin values by the urinary creatinine values. Regression analysis was used to determine the clinical utility of UACR and UHCR for detecting DN. The measured percentage values for $\mathrm{HbAl} \mathrm{c}$ were presented as mean \pm standard deviation. Relationship between $\mathrm{HbAlc}$ and UACR ratio as well as relationship between $\mathrm{HbAlc}$ and UHCR were assessed using Spearman Correlation coefficient. Statistical significance was set at $\mathrm{p}<0.05$.

\section{Laboratory Methods}

\section{Urinalysis}

Urinalysis was be carried out using urine reagent strip by Cortez Diagnostics, Inc. ${ }^{15}$

\section{Glycated Haemoglobin}

$\mathrm{HbA1c}$ was assayed using fluorescence immunoassay method by Finecaré ${ }^{\mathrm{TM}} .^{16}$

\section{Haptoglobin}

Haptoglobin was assayed using ELISA method by AssayMax ${ }^{\mathrm{TM}}$ Human Haptoglobin ELISA Kit. ${ }^{17}$

\section{Microalbumin}

Microalbumin was assayed using Immunoturbidimetric 
method by Microalbumin kit manufactured by Fortress Diagnostics Limited. ${ }^{18}$

\section{Creatinine}

Creatinine was estimated using modified Jaffe method. ${ }^{19}$

\section{Estimated glomerular filtration rate (eGFR)}

Kidney function was assessed by estimated glomerular filtration rate (eGFR) using Cockcroft and Gault formula. ${ }^{20}$

\section{Quality assurance}

All analytical tests were done according to the standard operating procedures. It involved the use of inter and intra-run of control sera along with the samples. Pre-analytical, analytical and post analytical precautions were observed.

Table 1: Age, Sex and BMI of Study Subjects

\begin{tabular}{|c|c|c|c|}
\hline Parameters & & Number & Frequency (\%) \\
\hline Gender & $\begin{array}{l}\text { Male } \\
\text { Female } \\
53.78 \pm 9.5 \text { years }\end{array}$ & $\begin{array}{l}35 \\
45\end{array}$ & $\begin{array}{l}44 \\
56\end{array}$ \\
\hline Age ( $\overline{\mathbf{x}} \pm$ SD) & & & \\
\hline $\begin{array}{l}\text { BMI }(\overline{\mathbf{x}} \pm \text { SD) } \\
\text { Duration of } \\
\text { Diabetes( }(\overline{\mathbf{x}} \pm \text { SD) }\end{array}$ & $\begin{array}{l}(\mathrm{Kg} / \mathrm{m} 2) 27.3 \pm 5.3 \\
8.5 \pm 4.8 \text { years }\end{array}$ & \multicolumn{2}{|c|}{ Peak: $36(45 \%)$ subjects 6-10 yr } \\
\hline
\end{tabular}

Table 2: Glycaemic Control (Hba1c) of Study Participants

\begin{tabular}{llll}
\hline $\mathbf{( \overline { \mathbf { x } } \pm \text { SD }} \quad 6.6 \pm 2.0^{0}$, & & \\
& & Number Frequency & $\mathbf{( \% )}$ \\
& Good control $(\leq 5.7)$ & 31 & 39 \\
Borderline $(5.7-6.4)$ & 13 & 16 \\
Poor control $(\geq 6.5)$ & 36 & 45 \\
\hline
\end{tabular}

Table 3: CKD Staging (NKF, 2002)

\begin{tabular}{|c|c|c|c|}
\hline \multicolumn{4}{|l|}{$(\bar{x} \pm S D$ eGFR: $98.4 \pm 40.3 \mathrm{~m} / / \mathrm{min} / 1.73 \mathrm{~m}$} \\
\hline & & Number & $\%$ \\
\hline & Stage $1(>90 \mathrm{ml} / \mathrm{min})$ & 20 & 25 \\
\hline & Stage $2(60.0-89.9 \mathrm{~m} / \mathrm{min})$ & 53 & 66 \\
\hline & Stage 3 $(30.0-59.9 \mathrm{ml} / \mathrm{min})$ & 7 & 9 \\
\hline
\end{tabular}

Table 4: Mean and Median of Bio-Chemical Characteristics

\begin{tabular}{lll}
\hline Characteristics & Mean \pm SD & Median(IQR) \\
& & \\
\hline Hap $(\mathrm{ng} / \mathrm{ml})$ & $93.6 \pm 70.1$ & $68.8(25.0-164.4)$ \\
UACR $(\mathrm{mg} / \mathrm{g})$ & $78.3 \pm 89.1$ & $51.5(28.3-78.0)$ \\
UHCR $(\mathrm{ng} / \mathrm{g})$ & $908.9 \pm 972.7$ & $529.0(119.0-1414.0)$ \\
\hline
\end{tabular}

Table 5 Comparing Biochemical Characteristics According to CKD Stages

\begin{tabular}{lccccc}
\hline Characteristics & Stage 1 & Stage 2 & \multicolumn{2}{c}{ Stage 3 } & \multicolumn{2}{c}{ Kruskal Walis p-value } \\
\cline { 2 - 6 } Urine Albumin & $5.3(4.5-6.0)$ & $7.5(6.8-10.0)$ & $19.5(19.5-19.5)$ & 61.023 & 0.001 \\
Haptoglobin & $21.3(11.3-25.0)$ & $140.6(58.8-172.2)$ & $193.8(187.5-197.5)$ & 60.934 & 0.001 \\
\hline
\end{tabular}

Table 6: Validity of UHCR for diabetic Nephropathy

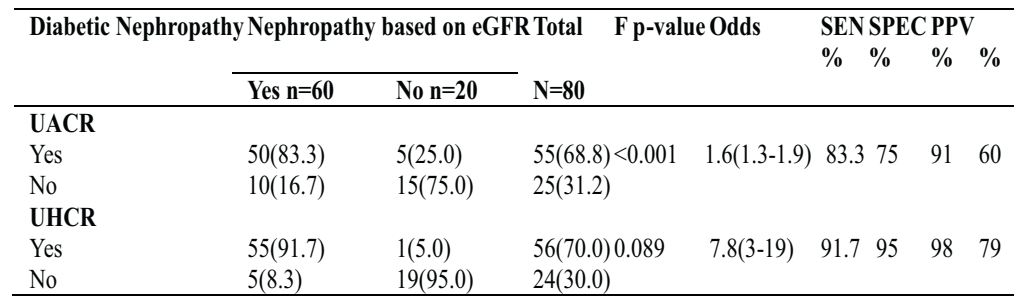

\section{DISCUSSION}

The present study recruited a total of eighty (80) type 2 diabetic patients of which $43.8 \%$ (35) were males and the remaining $56.2 \%$ (45) were the female participants resulting in 1:1.2 male to female ratio. The higher number of female participants was in keeping with studies done on diabetic patients in the same center by Umar in 2016 as well as in Abakaliki. $^{21}$

The mean age of the participant was $53.8 \pm 9.5$ years with the mean duration of the disease of $8.5 \pm 4.8$ years which is in concordance with the findings of Uloko et $_{\text {al }} .^{22}$ This finding is a suggests that middle age is the peak age incidence for diabetes in this environment. The mean body mass index of the study population was $27.3 \pm 5.3 \mathrm{~kg} / \mathrm{m}^{2}$ comprising of $37.6 \%$ of both underweight and normal weight while the remaining $62.5 \%$ were overweight and obese patients.

$\mathrm{HbA1}$ cdetermination documented a mean value of $6.6 \pm 2.0 \%$ with good glycaemic control recorded in $39 \%$ against $61.2 \%$ with poor glycaemic control. This connotes that the participants showed suboptimal glycaemic control which is in agreement with the study of Uloko $e t \mathrm{al}^{22}$ that most Nigerians diabetics have suboptimal glycemic control.

We observed a significant increasein the urine albumin, urine haptoglobin, glycated haemoglobin $(\mathrm{P}<0.05)$ across the stages of chronic kidney disease in this studywhich agrees with a study that higher level of albuminuria, glycated haemoglobin and haptoglobinuria are recorded in patients that developed early renal function decline. ${ }^{9}$ Linear regression model was used to predict diabetic nephropathy using UACR and UHCR. The analysis showed that eGFR reduces by $2.197 \mathrm{ml} / \mathrm{min}$ in a unit change of UACR compared to 27.969 $\mathrm{ml} / \mathrm{min}$ reduction in eGFR in a unit change of UHCR. This infers that UACR and UHCR predict nephropathy in type 2 diabetic patients 
independently, though UHCR is found to have more predictive ability than UACR as equally reported in the previous studies in USA, ${ }^{9}$ and Asia. ${ }^{10} \mathrm{We}$ then evaluated the prediction accuracy of UHCR independent of UACR and this revealed that UHCR predictive ability significantly out performed UACR in the prediction of diabetic.

We further correlated HbA1C with UACR as well as UHCR and this study demonstrate a strong positive relationship exists with UHCR correlating having a stronger correlation coefficient $(r=0.739)$ than UACR. This strong positive relationship was equally observed in a previous study among Asians, ${ }^{10}$ however is contrary to the study of Bhensdadia et $a l .{ }^{9} 2013$ that reported a weak positive relationship between UHCR and UACR.

Using logistic regression analysis, eGFR predicted 60 participants of the study population to have diabetic nephropathy. UACR predicted $83.3 \%(50)$ to have diabetic nephropathy with $83.3 \%$ sensitivity, $75 \%$ specificity, $91 \%$ positive predictive value and $60 \%$ negative predictive value while UHCR predicted $91.7 \%(55)$ to have diabetic nephropathy with $91.7 \%$ sensitivity, 95\% specificity, 98\% positive predictive power and $79 \%$ negative predictive power at $p<0.05$ level of significance. UHCR significantly predicts diabetic nephropathy.

\section{CONCLUSION}

This study for the first time established that UHCR has better diagnostic utility than UACR exhibited a very good positive correlation with glycaemic control. Based on its high sensitivity and specificity we therefore recommend its use in screening for nephropathy in diabetic patients.

Further multicenter studies and longitudinal studies are also recommended.

\section{Conflict of Interest}

None declared.

\section{REFERENCES}

1. Samuel NU. The role of novel biomarkers in predicting diabetic nephropathy: a review. Int J Nephrol Renovasc Dis. 2017; 10:221-231.

2. Rehman G, Hamayun M. Studies on diabetic nephropathy and secondary disease in type-1 diabetes. Int J Diabetes Dev Ctries. 2004; 24:50-55.
3. IDF Diabetes Atlas Group. Update of mortality attributable to diabetes for the IDF Diabetes Atlas: estimates for the year 2011. Diabetes Res Clin Pract. 2013;100(2):277-9.

4. Andrew UE, Musa BM, Ramalan MA, Ibrahim DG, Mohammed BM, Fabian HP, et al. Prevalence and risk factors for diabetes mellitus in Nigeria: A systemic review and meta-analysis. Diabetes Therapy. 2018;9(3):1307-1316.

5. Chinenye S, Young E. State of Diabetes Care in Nigeria. The Nigeria Health Journal. 2011;11(4):101-106.

6. Uwaezuoke SN. Prevention of diabetic nephropathy in children and adolescents: how effective are the current strategies? Int J Diabetol Vasc Disease Res. 2015;1(5):1-5.

7. Bunza FU, Mainasara AS, Dallatu MK, Bunza JM, Wasagu IZ. Prevalence of Microalbuminuria among diabetic patients in Usman Danfodiyo University Teaching Hospital, Sokoto. Bayero J Pure Appl Sci. 2014;7(1):1-5.

8. Guy M, Borzomato JK, Newall RG, Kalra PA, Price CP. Protein and albumin-to-creatinine ratios in random urines accurately predict $24 \mathrm{~h}$ protein an albumin loss in patients with kidney disease. Ann Clin Biochem. 2009; 46:468-476.

9. Bhensdadia NM, Hunt KJ, Lopes-Virella MF, Michael TJ, Mataria MR, Alge JL, et al. Urine haptoglobin levels predict early renal functional decline in patients with type 2 diabetes. Kidney Int. 2013;83(6):1136-43.

10. Jian-Jun L, Sylvia L, Melvin DS, Resham LG, Su CM. Urinary haptoglobin predicts rapid renal function decline in Asians with Type 2 diabetes and early kidney disease. J Clin Endocrinol Metab. 2016;101(10):3794-3802.

11. Araki S, Haneda M, Sugimoto T. Factors associated with frequent remission of microalbuminuria in patients with type 2 diabetes. Diabetes. 2005; 54:2983-2987.

12. . Nakhoul FM, Miller-Lotan R, Awad H, Asleh R, Jad $\mathrm{K}$, Nakhoul N, et al. Pharmacogenomic effect of vitamin $\mathrm{E}$ on kidney structure and function in transgenic mice with the haptoglobin 2-2 genotype and diabetes mellitus. Am J Physiol Renal Physiol. 2009; 296:830-838.

13. Wobeto VP, Zaccariotto TR, Sonati MF. Polymorphism of human haptoglobin and its clinical importance. Genet Mol Biol. 2008;31:602-608.

14. Susan R, Nigel S, Ana IC. Applying the principles: formula for determining sample size. Management Research. 2015; 1:1-4.

15. Free AH and Free HM. Urinalysis, Critical Discipline of Clinical Science. CRC Crit Rev Clin Lab Sci. 1972;3(4):481-531. 
16. Bunn HF. Nonenzymatic glycosylation of protein: relevance to diabetes. Am J Med. 1981; 70:331-338.

17. Van Vlierberghe H, Langlois M, Delanghe J. Clin Chim Acta. 2004;345(1):35-42.

18. Elvin LD, Bakkeren JA, Jansen MJ, Angelino CM, Nobel E, Munster PJ.Screening for microalbuminuria in patients with diabetes mellitus: frozen storage of urine samples decreases their albumin content. Clin Chem. 1989;35(2):308-310.

19. Jaffe XZ. Creatinine determination according to Jaffe. Hoppe Seylers Z Physiol Chem. 1886; 10:391.

20. Cockcroft DW, Gault MH. Prediction of creatinine clearance from serum creatinine. Nephrology. 1976; $16: 31-41$.

21. Ibekwe MU. Pattern of type 1 diabetes mellitus in Abakaliki Southeastern, Nigeria. Pediatr Oncall. 2011;8(7):59-62.

22. Uloko AE, Ofoegbu EN, Sunday C, Fasanmade OA, Fasanmade AA, Ogbera AO, et al. Profile of Nigerians with diabetes mellitus: results of a multicenter study. Indian J Endocrinol Metab. 2012;16(4):558-564. 


\title{
Comparison of Actual with Estimated Weight and Height in Children with Sickle Cell Anaemia in Lagos, Nigeria
}

Akodu SO*, Adekanmbi AF, Ogunlesi TA

Department of Paediatrics, Olabisi Onabanjo University Teaching Hospital, Sagamu, Ogun, Nigeria

*Corresponding Author: Akodu Samuel Olufemi. Department of Paediatrics, Olabisi Onabanjo University Teaching Hospital, Sagamu, Ogun, Nigeria.

\begin{abstract}
Sickle cell disorders are the most common genetic disorders worldwide as well as in Nigeria. The weight and height are the most used anthropometric measurements in paediatric practice for the calculation of many parameters. The objective is to determine the reliability of weight and height estimates among children with sickle cell anaemia compared with measured weight and height. A random sample of SCA children aged eight months to 12 years was studied. Height and weight were measured using standard methods, while BMI was estimated using $\mathrm{kg} / \mathrm{m} 2$. These were compared with estimated weight, height and BMI. Five subjects were adjudged obese using estimated BMI: three of these five subjects were identified as obese using actual BMI. Regression analysis showed that there appears to be more positive linear relationship for weight and length/height among children aged 1- 6 years. The measured mean weight and BMI were significantly lower than the estimated mean values. The overall mean of estimated length/height did not differ significantly from overall mean of the actual length/height. In comparison with the actual BMI, the estimated BMI did not identify any of the subjects with either thinness or overweight while children with obesity were over-estimated. The formula methods of estimating weights and heights for the various ages in children with sickle cell anaemia are over-estimating their actual values; this is more obvious for weight.
\end{abstract}

Keywords: Measured, Estimated,Weight, Height, Body mass index

\section{INTRODUCTION}

$\mathrm{S}_{\mathrm{s}}^{\mathrm{i}}$ ickle cell anaemia is one of the commonest single gene disorders in man with variable distribution in different parts of the world and variable clinical manifestations. ${ }^{1}$ In Nigeria, the prevalence of sickle cell trait is about $25 \%$ while the homozygous state is found in about $3 \%$ of the population ${ }^{2}$. Africa has $70 \%$ of the world's annual figure of 300,000 affected new births. ${ }^{3}$ Nigeria has the highest burden worldwide. ${ }^{4} \mathrm{~A}$ recent WHO report estimated that approximately 20 per 1,000 births in Nigeria are affected by sickle cell anemia, giving a total of about 150,000 affected children born every year in Nigeria alone. ${ }^{5}$ The periodic measurement of height and weight are important parts of routine healthcare for all children, including those with sickle cell anaemia, and comparison of these measurements against reference standards or norms can serve as a screening tool for nutritional problems. Sickle cell anaemia commonly affects growth, leading to low mean weight, low mean height and decreased height velocity. ${ }^{6-10}$ However, there are difficulties in obtaining accurate measurements of height in children with sickle cell anaemia that have 
incapacitating conditions because the pain of vaso-occlusive crisis in patients with sickle cell disease is excruciating, and incapacitating to enable height measurement. Therefore under these difficult circumstances the weight and height have to be estimated. Children with sickle cell anaemia are vulnerable to growth deficits, of which stunting in height is one of those commonly described. ${ }^{6-10}$ The weight and height for age estimated using the universally accepted formulae uses a specific set of equations validated on the general population without sickle cell anaemia. Although the technique and these equations are widely used, to date no study has been published which established that it's equally useful among children with sickle cell anaemia.

This study was carried out to determine whether estimated weight and height among children with sickle cell anaemia agrees with measured weight and height. In addition we investigated whether Body Mass Index (BMI) calculated on the basis of estimated weight and height values agree with BMI values calculated on the basis of measured weight and height. It was a cross-sectional and descriptive study.

\section{MATERIALSAND METHODS}

The study subjects were children aged eight months to 12 years with sickle cell anaemia attending the sickle cell disease clinic of the Department of Paediatrics of Lagos State University Teaching Hospital, Ikeja, Lagos in South west Nigeria based on the clinic attendance records. The included children were in a steady state i.e. absence of any crisis in the preceding four weeks, no recent drop in the haemoglobin level and absence of any symptoms or sign attributable to an acute illness.11 They were also not taking medications known to affect growth e.g. steroids. All children, or parents when it concerned young children, gave informed consent for inclusion in the study.

Study subjects were recruited consecutively until the desired sample size was attained. This lasted three months. The study was performed according to the guidelines of the Medical Ethics Committee of the Lagos State University Teaching Hospital. The sample size was calculated with $90 \%$ power and $5 \%$ significance level (two-tailed) for prevalence of stunting of $25 \%$ reported by Henderson et al12 among children with sickle cell disease. In order to accommodate possible attrition or unforeseen errors in completing the study questionnaire, an additional 20\% (14 subjects) of the calculated figure was recruited to bring the figure to 86 , which was approximated to 90 subjects.

Subjects' weights were measured barefooted and wearing light clothing. Weight measurements were taken on a Seca 761 series mechanical floor scale to the nearest $0.1 \mathrm{Kg}$. Children two years of age and older had their heights measured using a stadiometer while the length of those below two years were measured using an infantometer. The various linear measurements were taken three times. Variation among measurements was not more than $0.3 \mathrm{~cm}$. The mean of these three measurements was recorded. For the purpose of quality assurance standardization of the instruments were done after every 10 measurements.

The weight and height for age were also estimated using the universally accepted formulae. The weight of the study subjects were estimated using the following formula ${ }^{13}$

For children aged less than one year: $(n+9) / 2$, where "n" is age in months.

For children aged $1-6$ years: $(2 n+8)$, where " $n$ " is age in years

For children aged $7-12$ years: $(7 n-5) / 2$, where " $n$ " is age in years

For the height estimate, the formula $(6 n+77)$, where " $n$ " is age in years, as recommended for children aged $2-12$ years was applied. The estimated height for children aged one year was taken as $75 \mathrm{~cm} .13$ The body mass index was calculated using the formula Weight in $\mathrm{kg} /$ Height in $\mathrm{m} 2(\mathrm{Kg} / \mathrm{m} 2) 14 \mathrm{Z}$ scores were generated for actual BMI as well as the estimated BMI.

The data were entered into a standard computer system. The data was analysed using Statistical Package for Social Science (SPSS) version 19.0. Scatter diagram was plotted to determine the relationship between actual and estimated parameters. The mean, standard deviation and other parameters of statistical location were generated as necessary. Tests of statistical significance between means of actual and estimated parameters were by paired Student $\mathrm{t}-$ test. Level of significance was set at $p<0.05$.

\section{Operational definition}

Actual weight - weight of patient measured with Seca by researcher

Actual height - height of patient measured with infantometer or stadiometer by researcher

Actual BMI - BMI of patient calculated on the basis of actual weight and height

Estimated weight - weight of patient estimated by 
researcher

Estimated height - height of patient estimated by researcher Estimated BMI - BMI of patient calculated on the basis of estimated weight and height

\section{RESULTS}

\section{Characteristics of the study population}

A total of 90 children who met the study criteria, were recruited over a study period of three months. The age and gender distribution of the study patients are given in Table I. Overall, the age of the subjects ranged from nine months to 12 years, with a mean of $67.73( \pm 43.78)$ months. The modal age group was $1-6$ years. The male to female ratio was $1: 1$.

\section{Comparison of mean actual and estimated parameters of study subjects}

This phase of analysis compared the measured parameters with the estimated parameters - Table II. The measured mean weight and BMI were significantly lower than the estimated mean of values. The overall mean of estimated length/height did not differ significantly from overall mean of the actual length/height. Further analysis of comparison between actual and estimated parameters shows that the least mean difference between estimated parameters and actual parameters was observed with length/height $(0.6 \pm 9.5 \mathrm{~cm})$ and highest with weight $(2.9 \pm 5.0 \mathrm{Kg})$.

\section{Scatter plot of actual and estimated parameters}

The scatter diagrams showing the relationship between actual and estimated parameters are shown in figures 1,2, and 3 for weight, length/height, and BMI respectively. The plots showed linear relationship between actual and estimated parameters. However, there appears to be more positive linear relationship for weight and length/height among children aged $1-6$ years than those aged $<$ one year and $7-12$ years (fig 1 and 2).

\section{Number of subjects in BMI groups: BMI based on actual weight and length/height vs. BMI based on estimates of those values}

Z-scores were generated for both actual and estimated BMI derived by actual and estimated weigh and length/height. On the basis of the z scores, study subjects were then categorized into thin, overweight and obese. BMI Z-score cut-points of $<$ $-2.0,>+1.0$, and $>+2.0$ are recommended to define thinness, overweight and obese.15 Table III shows the prevalence of thinness, overweight and obesity using both the actual (observed) and the standardized BMI values. Table III shows that, altogether, one subjects were classified as thin on the basis of z scores of actual BMI, on the contrary none subject were identified as thin using $\mathrm{z}$ scores of estimated BMI. Two subjects were classified as overweight on the basis of $\mathrm{z}$ scores of actual BMI while none subject were identified as overweight using $\mathrm{z}$ scores of estimated BMI. Also, five subjects were adjudged obese using estimated BMI: three of these five subjects were identified as obese using actual BMI.

Table I - Demographic characteristics of study populations

\begin{tabular}{lll}
\hline Character & Number & Percentage (\%) \\
\hline Gender & & \\
Male & 45 & 50.0 \\
Female & 45 & 50.0 \\
Total & 90 & 100.0 \\
\hline Age Group & & \\
$<1$ year & 5 & 5.6 \\
$1-6$ years & 49 & 54.4 \\
7 - 12 years & 36 & 40.0 \\
\hline
\end{tabular}

Table II: Mean actual and estimated anthropometric measurements of study subjects

\begin{tabular}{|c|c|c|c|c|}
\hline \multicolumn{5}{|c|}{ Anthropometric Measures } \\
\hline & $\begin{array}{l}\text { Actual } \\
\text { Mean (SD) }\end{array}$ & $\begin{array}{l}\text { Estimate } \\
\text { Mean (SD) }\end{array}$ & t- value & p- value \\
\hline Weight & $17.9(7.3)$ & $20.8(10.1)$ & 0.885 & $0.029^{*}$ \\
\hline Height & $109.2(23.8)$ & $109.8(23.6)$ & 0.920 & 0.865 \\
\hline BMI & $14.7(3.2)$ & $15.9(1.8)$ & 0.118 & $0.002 *$ \\
\hline
\end{tabular}

Table III: Comparison of BMI based on actual weight and length/height vs. BMI based on estimates of those values

\begin{tabular}{llll}
\hline & Thinness & 0verweight & Obesity \\
Estimated BMI & 0 & 0 & 5 \\
Actual BMI & 1 & 2 & 3 \\
\hline
\end{tabular}




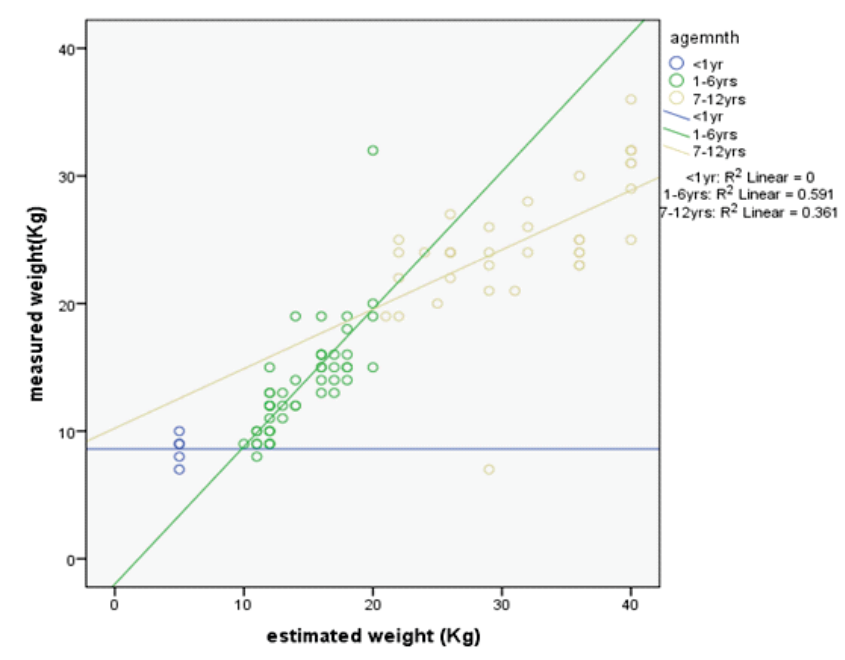

Fig 1: scatter plot of actual weight and estimated weight

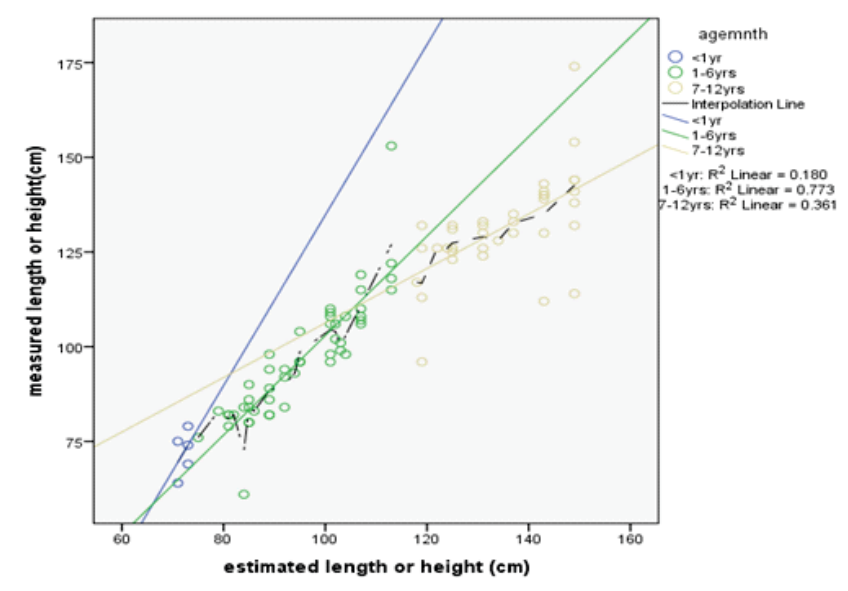

Fig 2: scatter plot of actual length/height and estimated length/height

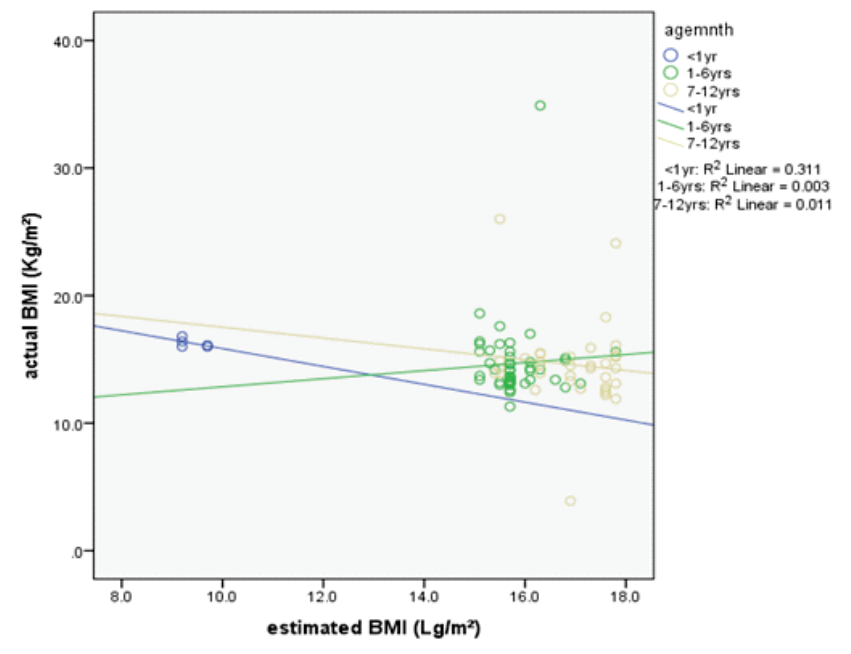

Fig 3: scatter plot of actual BMI and estimated BMI

\section{DISCUSSION}

The measurement of weight, height/length, and body mass index is an invaluable tool in paediatric settings. They are measurement required for the evaluation of growth, calculation of nutritional indices, prediction and standardization of physiological variables such as lung volumes, ${ }^{16}$ glomerular filtration rate, metabolic rate, and for the tailoring of drug dosage in patients. ${ }^{17}$ In the emergency situations, fast and accurate methods of weight and height estimation are needed for immediate therapeutic interventions in order to save lives of children with sickle cell anaemia in crisis. Many estimation methods currently exist for general paediatric usage but most may not be relevant in children with sickle cell anaemia resulting in the fact that the formula estimation of weight or height may be overestimating the actual value in many of these children. Present study is the first attempt to determine whether estimated weight and height among children with sickle cell anaemia agrees with measured weight and height.

The present study shows that estimates of weight, height/length and BMI among children with sickle cell anaemia done using standard formula by healthcare workers were generally adequate, although overestimation of weight and height were as large as $2.9 \mathrm{Kg}$ and $0.6 \mathrm{~cm}$ respectively. Length/height estimates were more accurate than weight estimates which was revealed by the relative closeness of the mean estimated height/length values to the mean measured height/length values. The over-estimation of weight and height using standard formula methods will result in significant over - dosing of some emergency drugs such as opoids for analgesia among children with sickle cell anaemia which will be more pronounced using estimated weight. The estimated mean weight value was significantly higher than the actual weight in the current study. This is most likely a consequence of effect of sickle cell anaemia on childhood growth. There was no consistent pattern observed between the estimated and actual weight. These observed differences may also be due to disparity in severity of illness among the study subjects which is incomparable. The reason why the estimated mean weight and not the mean height or both was significantly higher than the actual parameters was not apparent as both are linear growth parameters and which should be more affected by sickle cell disorder is difficult to predict.

In this present study the strongest positive correlations for 
weight and length/height among children aged $1-6$ years compared with aged below one year and $7-12$ years. The findings are not surprising because both the weight and length/height variables are linear measurements which increase physiologically in the same direction with age. Considering the fact that under-nutrition is prevalent in Nigeria especially among under -five children ${ }^{18,19}$ and sickle cell anaemia commonly affects linear growth, ${ }^{6-10}$ the formula over-estimating the weights and heights of the subjects was not an incidental findings. These formulae as applied in the current study were proposed many years ago. The growth pattern of children may have changed with poor nutrition as a result of worsening economic situation. Not surprisingly, we found a significantly higher estimated BMI compared with actual BMI. For the purpose of this study, actual BMI was calculated on the basis of actual height and weight, and estimated BMI was calculated on the basis of estimated height and weight values. With a higher estimated weight values than actual and comparable values for both actual and estimated values, if BMI is estimated in this case, estimation of BMI may lead to misleading results. In our study, patients with the lowest BMI were more likely to have an underestimated body weight, and patients with the highest BMI were more likely to have body weight overestimated.

In the current study the estimated BMI derived from estimated weight and height was observed not to identify the only one and two subjects with thinness and overweight respectively. On the contrary the estimated BMI were more likely to overestimate subjects with obesity. It is attractive to conclude that estimated BMI is not a good tool to identify nutritional abnormalities among children with sickle cell anaemia as they may fall into a wrong BMI category.

\section{CONCLUSION}

We conclude that estimation of length/height, weight, and BMI by healthcare workers is adequate in general. Height is generally better estimated than is weight. Overestimation of body fat content occurred particularly in the thinness and overweight subjects, whereas overestimation of body fat content occurred especially in subjects with a high BMI in obesity category. There is need for a multi-centre cohort study to test the various formulae in our children.

\section{Limitation}

The major limitation of the study is the small sample number which provided too small of affected patients with growth deficit by sickle cell anaemia to make conclusive remarks. There is a need for collaborative, multicentre study involving larger pool of children with varying severity of sickle cell anaemia to confirm whether the standard equations are equally useful among children with sickle cell anaemia. The present study is to be considered as a first step in assessing the reliability of the standard formula among children with sickle cell anaemia.

\section{Conflict of Interest}

None declared.

\section{REFERENCES}

1. Serjeant GR, Serjeant BE. Sickle cell disease. $3^{\text {rd }}$ ed. New York: Oxford University Press; 2001.

2. Adekile AD, Adeodu OO. Haemoglobinopathies. In: Azubuike JC, Nkanginieme KEO (editors). Textbook of Paediatrics and Child Health in a Tropical Region. 2nd ed. Owerri: African Educational Services; 2007; $373-90$.

3. Makani J, Konba AN, Cox SE, Oruo J, Mwamtemi $\mathrm{K}$, Kitundu J, et al. Malaria in patients with sickle cell anaemia: burden, risk factors, and outcome at the outpatient clinic and during hospitalization. Blood 2010; 115: 215 - 220.

4. Iwalokun BA, Iwalokun SO, Hodonu SO, Aina AO, Agomo PU. Serum levels of leptin in Nigerian patients with sickle cell anaemia. BMC Blood Disorders 2011; 11: 1 - 11

5. World Health Organization. Report by the Secretariat of the Fifty-ninth World Health Assembly A59/9 2006

6. Barden EM, Kawchak DA, Ohene-Frempong K, Stallings VA, Zemel BS. Body composition in children with sickle cell disease. Am J Clin Nutr 2002; 76: 218 - 25

7. Mukherjee MB, Gangakhedkar RR. Physical growth of children with sickle cell disease. Indian J Hum Genet 2004; 10: 70 - 2

8. Silva C. Growth Deficits in Children with Sickle Cell Disease. Arch Med Res 2003; 33: 308 - 12

9. Emodi KJ, Kaine WN. Weights, Heights, and Quetelet's indices of children with sickle cell anaemia (sicklers). Nig J Paediatr 1996; 23: 37 - 41.

10. Ogunrinde GO, Yakubu AM, Akinyanju OO. Anthropometric measures and zinc status of children with sickle cell anaemia in Zaria. Nig J Paediatr 2000; 27: 64 - 9 .

11. Awotua-Efebo O, Alikor EAO, Nkanginieme KEO. Malaria parasite density and splenic status by ultrasonography in stable sickle cell anaemia (HbSS) children. Nig J Med 2004; 13: 40 - 4. 
12. Henderson RA, Saavedra JM, Dover GJ. Prevalence of impaired growth in children with homozygous sickle cell anemia. Am J Med Sci 1994; 307: $405-$ 7.

13. Keane V. Assessment of growth. In Nelson textbook of paediatrics, $18^{\text {th }}$ edition

14. Akodu SO, Njokanma OF, Kehinde OA. Cormic index in Nigerian children with sickle cell anaemia. Anemia 2014

15. WHO and UNICEF. WHO child growth standards and the identification of severe acute malnutrition in infants and children A Joint Statement by the World Health Organization and the United Nations Children's Fund. Geneva: WHO and UNICEF 2009.

16. Golshan M, Crapo RO, Amra B, Jensen RI, Golshan $\mathrm{R}$. Arm span as an independent predictor of pulmonary function parameters: validation and reference values. Respirology 2007; 12: $361-6$

17. Zverev YP. Relationship between arm span and stature in Malawian adults. Annals of Human Biology 2003; 30: 739 - 43.

18. Cheymol G. Effects of obesity on pharmacokinetics: implications of drug therapy. Clinical pharmacokinetics 2000;39(2): 215-231.

19. Sebanjo IO, Olayiwola IO, Afolabi WA, Sebanjo OC. Maternal and child undernutrition in rural and urban communities of Lagos State, Nigeria: the relationship and risk factors. BMC Research Notes 2013, 6:286 


\title{
Glucose-6- Phosphate Dehydrogenase Activity in Newborn in Jos: A Necessary Evaluation for Icteric Neonates
}

\author{
Jatau ED. ${ }^{1^{*}}$, Toma BO. ${ }^{2}$, Egesie OJ. ${ }^{1}$, Damulak OD. ${ }^{1}$, Ayuba Z. ${ }^{1}$, Ewuga OJ., Ma'an VT. ${ }^{3}$ \\ ${ }^{I}$ Department of Haematology and Blood Transfusion, Jos University Teaching Hospital. \\ ${ }^{2}$ Department of Paediatrics, Jos University Teaching Hospital. \\ ${ }^{3}$ Department of Haematology and Blood Transfusion, Federal Medical Centre, Keffi.
}

\begin{abstract}
Red blood cell glucose-6-phosphate dehydrogenase (G6PD) is a key regulatory enzyme with the major role of meeting the cellular need for reductive biosynthesis and maintenance of redox status. G6PD deficiency is a common inherited enzyme defect associated with severe neonatal hyperbilirubinaemia that can result in permanent neurologic damage or death. This study was aimed at estimating the level of G6PD activity among icteric neonates to assess its usefulness in the evaluation of icteric neonates in Jos. One hundred and fifty icteric neonates ( 92 males and 58 females) whose parents consented were consecutively enrolled as they presented at the Special Care Baby Units (SCBU) of the Jos University Teaching Hospital (JUTH), Bingham University Teaching Hospital (BhUTH), and the Plateau State Specialist Hospital (PSSH), Jos. These subjects had their G6PD activity levels assayed using the Pointe Quantitative Diagnostic Kit (USA) while other relevant clinical information was obtained using a questionnaire. G6PD activity of the icteric neonates ranged between 0.54 and $24.18 \mathrm{IU} / \mathrm{gHb}$ with a mean of $8.02 \pm 4.87 \mathrm{IU} / \mathrm{gHb}$. Sixty-one ( $40.7 \%$ ), comprising 45 males and 16 female neonates were G6PD deficient with mean G6PD activity of $3.79 \pm 1.37 \mathrm{IU} / \mathrm{gHb}$ while eighty-nine $(59.3 \%)$ were G6PD normal with a mean G6PD activity of $10.92 \pm 4.24$ $\mathrm{IU} / \mathrm{gHb}$. G6PD activity in icteric neonates in Jos varies widely with a relatively high proportion of these neonates being G6PD deficient. Determination of G6PD activity in icteric neonates should therefore form an important evaluation tool for identification and intervention in those with the deficiency.
\end{abstract}

*Corresponding Author: Jatau ED. Department of Haematology and Blood Transfusion, Jos University Teaching Hospital.Email: ezradjatau@gmail.com

Keywords: Evaluation,Glucose-6-phosphatedehydrogenase,Icteric,Neonates

\section{INTRODUCTION}

G lucose-6-phosphate dehydrogenase (G6PD) is a cytoplasmic enzyme distributed in all cells and catalyses glucose-6-phosphate oxidation to 6phosphogluconolactone, converting the co-enzyme nicotinamide adenine dinucleotide phosphate (NADP) to its reduced form (NADPH). NADPH is required for reduction of oxidized glutathione (GSSG) to its reduced form (GSH) by glutathione reductase which helps protect the red blood cells from oxidative stress and reactive oxygen species. ${ }^{1}$ The red blood cell (RBC) is vulnerable to injury by exogenous and endogenous oxidants, G6PD enzyme deficiency or its impaired function, reduces the ability of the red blood cell to protect itself against oxidative injuries. ${ }^{1}$ This results in haemolytic anaemia of varying severity as well as neonatal hyperbilirubinaemia a major cause of neonatal morbidity and mortality. ${ }^{1,2}$ 
Glucose-6-phosphate dehydrogenase deficiency, an inherited $\mathrm{X}$-linked disorder is the most common of the red cell enzymes defect affecting about 400 million people globally with highest prevalence in the tropics, subtropics and in the Mediterranean countries. Migration has contributed to the worldwide distribution of G6PD deficiency with the prevalence varying among different ethnic groups. ${ }^{2}$ In Nigeria, the prevalence of G6PD deficiency ranges from 4$26 \%$ with the male population and icteric neonates having a prevalence of $20-26 \%$ and $20.5-35.3 \%$ respectively. ${ }^{3,4}$ It affects hemizygous males, homozygous females, about $10 \%$ of heterozygous females and those with Turner's syndrome ${ }^{5}$ The most significant manifestations of G6PD deficiency are drug-induced haemolysis, non-spherocytic haemolytic anaemia, favism, and neonatal hyperbilirubinaemia that is usually severe and prolonged with a tendency to developing brain damage, or death. ${ }^{5}$

Hyperbilirubinaemia in G6PD deficient neonates exposed to icterogenic agents occurs in association with many factors that include immaturity of their liver conjugating enzymes system, method of feeding, and neonatal sepsis. ${ }^{5,6}$ It is seldom associated with mortality when detected early however management of hyperbilirubinaemia remains a challenge for neonatal medicine in resource poor settings like ours. ${ }^{6,7}$ It is therefore necessary to assess the enzyme activity in the neonates so that those with the deficiency can be identified early and appropriate intervention instituted for better outcomes

\section{MATERIALSAND METHODS}

This cross-sectional study was carried out at the Special Care Baby Units of Jos University Teaching Hospital, Bingham University Teaching Hospital, and Plateau State Specialist Hospital, Jos between March 2013 and February 2014 following approval from the Human Research and Ethics Committees of these institutions. All Jaundiced neonates admitted into the SCBUs whose parents gave consent were enrolled excluding those with previous history of blood transfusion, cephalhaematomas, bleeding tendencies and asphyxia. Venous blood was taken into an EDTA and plain sample bottle for full blood count (FBC), G6PD enzyme assay, and bilirubin assay using standard laboratory procedures. G6PD enzyme assay was carried out using reagents and control samples manufactured by the Pointe Reagent Company (USA). Red blood cell G6PD enzyme activity $<6.0 \mathrm{IU} / \mathrm{gHb}$ was considered deficient.

\section{Statistical analysis}

Data was analyzed using EPI-info Version 6 software. Mean, median, mode and standard deviation (SD) were used to describe continuous data. Students' t-test was used to assess the significance between means of two groups. Chi-square was used to compare categorical data. Results were presented in tables and chart. $P$ value $\leq 0.05$ was considered statistically significant

\section{RESULTS}

One hundred and fifty icteric neonates comprising 92 (61.3\%) males and 58 (38.7\%) females $(\mathrm{M}: \mathrm{F}=1.6: 1)$ were studied. Their mean age at presentation was $3.28 \pm 3.11$ days. Majority, 133 (88.6\%) were aged between 0 and 5 days at presentation. (Fig1).

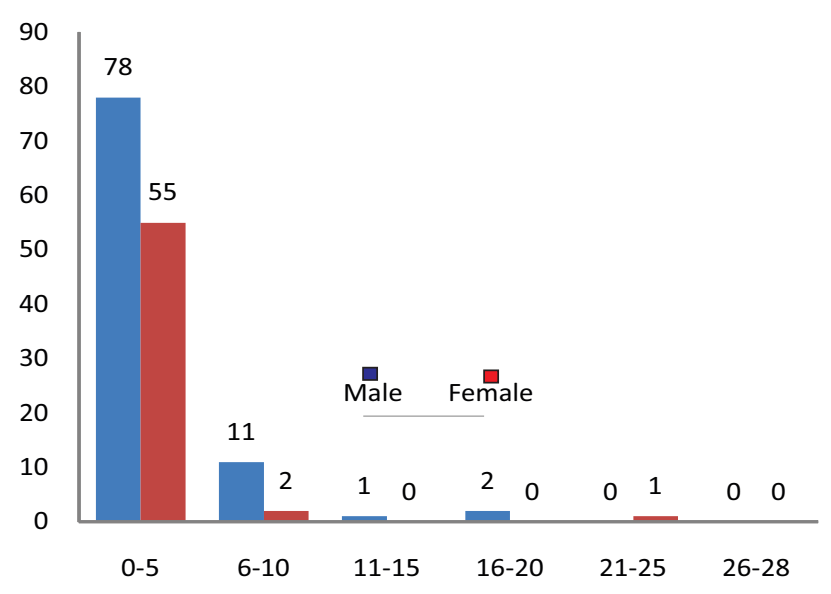

Figure 1: Age and sex distribution of neonates presenting with jaundice in tertiary health facilities in Jos between March 2013 and February2014

Laboratory parameters of the neonates showed a mean and median haemoglobin concentration of $15.90 \pm 2.23 \mathrm{~g} / \mathrm{dl}$ and $15.69 \mathrm{~g} / \mathrm{dl}$ respectively and a range of 11.33 to $22.30 \mathrm{~g} / \mathrm{dl}$ while the mean haematocrit was $0.47 \pm 0.06$, median 0.45 and a range of $0.34-0.67$. The mean serum bilirubin was $205.01 \pm$ $96.57 \mu \mathrm{mol} / \mathrm{L}$ with mode of $184.50 \mu \mathrm{mol} / \mathrm{L}$ and a range of 86.70 to $06.00 \mu \mathrm{mol} / \mathrm{L}$.(Table 1$)$ 
Table 1- Relevant laboratory parameters of neonates presenting with jaundice in tertiary health facilities in Jos between March 2013 and February 2014 Parameters

$$
\text { n; (150) }
$$

\begin{tabular}{ll}
\hline Haemoglobin concentration $(\mathrm{g} / \mathrm{dl}$; mean $\pm \mathrm{SD})$ & $15.90 \pm 2.23$ \\
Haematocrit $($ mean $\pm \mathrm{SD})$ & $0.47 \pm 0.06$ \\
Serum bilirubin $(\mu \mathrm{mol} / \mathrm{L}$; mean $\pm \mathrm{SD})$ & $205.01 \pm 96.57$ \\
G6PD activity $(\mathrm{IU} / \mathrm{gHb}$; mean $+\mathrm{SD})$ & $8.02 \pm 4.87$ \\
\hline
\end{tabular}

G6PD activity ranged from $0.54-24.18 \mathrm{IU} / \mathrm{gHb}$ with a mean activity of 8.02 $\pm 4.87 \mathrm{IU} / \mathrm{gHb}$ and median of $7.19 \mathrm{IU} / \mathrm{gHb}$. Sixty-one $(40.7 \%)$ of them were G6PD deficient comprising 45 males and 16 females. Their mean G6PD activity was $3.53 \pm 1.34 \mathrm{IU} / \mathrm{gHb}$ and $4.53 \pm 1.18 \mathrm{IU} / \mathrm{gHb}$ respectively. There was a statistically significant difference between the mean G6PD activity of the male and female icteric neonates $(\mathrm{t}=2.64, \mathrm{P}=0.01)$ (Table 2$)$.

Table 2- G6PD activity and Sex of neonates presenting with jaundice in tertiary health facilities in Jos between March 2013 and February 2014

\begin{tabular}{|c|c|c|c|c|c|c|c|}
\hline \multicolumn{8}{|c|}{ Sex } \\
\hline \multicolumn{4}{|c|}{ Male } & \multicolumn{4}{|l|}{ Female } \\
\hline G6PD status & n $\quad(\%)$ & G6PD activity* & n $\quad(\%)$ & G6PD activity* & $\mathbf{t}$ & $\mathbf{P}$ & Total \\
\hline G6PD deficient & $45(48.9)$ & $3.53 \pm 1.34$ & $16(27.6)$ & $4.53 \pm 1.18$ & 2.64 & 0.01 & 61 \\
\hline G6PD normal & $47(51.1)$ & $10.86 \pm 4.60$ & $42(72.4)$ & $10.91 \pm 3.86$ & 0.14 & 0.89 & 89 \\
\hline Total & $92(100)$ & & $58(100)$ & & & & 150 \\
\hline Parenthesis $=P e$ & entage tota & & $a n \pm S D) I$ & $g H b$ & & & \\
\hline
\end{tabular}

Twenty two (36.1\%) of the G6PD deficient neonates and $40(44.9 \%)$ of the G6PD normal neonates had mild hyperbilirubinaemia with a mean serum bilirubin of $132.3 \pm 24.6 \mu \mathrm{mol} / \mathrm{L}$ and $135.8 \pm 28.9 \mu \mathrm{mol} / \mathrm{L}$ respectively. Hyperbilirubinaemia in relation to G6PD status did not show any statistical significant difference, $\mathrm{P}>0.05$. (Table 3 )

Table 3- G6PD status and severity of hyper-bilirubinaemia of neonates presenting with jaundice in tertiary health facilities in Jos between March 2013 and February 2014

\section{G6PD status}

\begin{tabular}{lcccccccc}
\hline & \multicolumn{3}{c}{ Deficient } & \multicolumn{3}{c}{ Normal } \\
\hline Hyper-bilirubinaemia & $\mathbf{n}$ & $\%$ & mean SB & $\mathbf{n}$ & $\mathbf{\%}$ & mean SB & $\mathbf{t}$ & $\mathbf{P}$ \\
\hline Mild & 22 & 36.1 & $132.3 \pm 24.6$ & 40 & 44.9 & $135.8 \pm 28.9$ & 0.70 & 0.49 \\
Moderate & 24 & 39.3 & $205.6 \pm 26.6$ & 36 & 40.4 & $203.7 \pm 24.2$ & 0.29 & 0.78 \\
Severe & 15 & 24.6 & $383.1 \pm 110.1$ & 13 & 14.6 & $338.9 \pm 100.4$ & 1.10 & 0.28 \\
\hline Total & 61 & 100 & & 89 & 100 & & & \\
\hline
\end{tabular}

\section{DISCUSSION}

The mean G6PD activity of the icteric neonates in this study was $8.02 \pm 4.87 \mathrm{IU} / \mathrm{gHb}$ while that of deficient icteric neonates was $3.79 \pm 1.37 \mathrm{IU} / \mathrm{gHb}$. The proportion of neonates with G6PD deficiency was $40.7 \%$. Azma et al in Malaysia reported a mean G6PD activity of $12.43 \pm 2.28 \mathrm{IU} / \mathrm{gHb}$ (Normal; 10.15-14.71 IU/gHb) in neonates while Reclos et al in Greece had an average G6PD activity level of $10.6 \mathrm{IU} / \mathrm{gHb}$ (Normal; $\geq 6.4 \mathrm{IU} / \mathrm{gHb}$ ). ${ }^{7}$,

${ }^{8}$ These estimations were carried out using different G6PD assay kits and in different geographical locations which could have contributed to the variance in mean G6PD activity observed in this study.

The mean G6PD level of the deficient neonates in this study was higher than the finding of 1.50 $\pm 0.02 \mathrm{IU} / \mathrm{gHb}$ by Uko et al in Calabar. Similarly, Obasa et al in Ilorin while determining G6PD levels in babies delivered at University of Ilorin Teaching Hospital reported a normal value of $5.72 \pm 2.45 \mathrm{IU} / \mathrm{gHb}$ in females and $4.99 \pm 2.30 \mathrm{IU} / \mathrm{gHb}$ in males while babies with G6PD deficiency had comparable G6PD enzyme activities of $2.1 \pm$ 0.66 and $2.05 \pm 0.60 \mathrm{IU} / \mathrm{gHb}$ in males and females respectively. ${ }^{10}$ George et al in Port Harcourt, Nigeria, considered values below $40 \%$ of normal adult G6PD activity level (8.83 $\pm 1.59 \mathrm{IU} / \mathrm{gHb}$ ) as deficient. ${ }^{11}$

He reported a mean G6PD level for deficient Icteric newborns to be $17.3 \pm 10.9 \%$ with a G6PD deficiency prevalence of $52.5 \%$. In a study conducted in Brazil, G6PD activity $<2.0$ $\mathrm{IU} / \mathrm{gHb}$ was considered profound deficiency, 2.0-6.0 IU/gHb as partially deficient while activity of $>6.0 \mathrm{IU} / \mathrm{gHb}$ was termed normal. Prevalence of G6PD deficiency reported in the study in Brazil was 7.9\%. ${ }^{12}$ These findings are not surprising as it has been reported in Africa, South of the Sahara, that three different G6PD variants with polymorphic gene frequencies and activity exist. ${ }^{13}$ G6PD B is the commonest 
with normal enzyme activity followed by G6PD A ${ }^{+}$with $98 \%$ activity without association with haemolysis. ${ }^{13}$ The third variant G6PD A ${ }^{-}$with an activity of $20 \%$ is associated with haemolysis especially when the red cells are exposed to certain foods, chemicals or drugs. ${ }^{13}$ The difference in enzyme activity may be attributed to the G6PD enzyme variant amongst the ethnic population studied warranting variable reference ranges. This is corroborated by the report that in African populations, three different G6PD genotypes are recognised in males $\left(\mathrm{GdA}^{+}, \mathrm{GdB}\right.$ and $\left.\mathrm{GdA}^{-}\right)$whilst in females six genotypes are recognised $\left(\mathrm{GdB} / \mathrm{GdB}, \mathrm{GdA}^{+} / \mathrm{GdB}\right.$, $\mathrm{GdA}^{+} / \mathrm{GdA}^{+}, \mathrm{GdB} / \mathrm{GdA}^{-}, \mathrm{GdA}^{-} / \mathrm{GdA}^{-}$and $\left.\mathrm{GdA}^{+} / \mathrm{GdA}^{-}\right) .{ }^{13}$ Ademowo et al in a study in Nigeria, demonstrated that each of these genotypes expresses varying levels of enzyme activity ranging from $9.5 \pm 3.7 \mathrm{IU} / \mathrm{gHb}$ in $\mathrm{GdB}$ in males to $1.7 \pm 1.1 \mathrm{IU} / \mathrm{gHb}$ in $\mathrm{GdA}^{-} / \mathrm{GdA}^{-}$genotype in females. $^{13}$

The proportion of icteric neonates with G6PD deficiency in this study is similar to the finding in Zaria, North West and Ilorin, North Central Nigeria where Ahmed et al, and Amiwero et al reported a prevalence of $40 \%$ and $43 \%$ respectively. ${ }^{14,15}$ Prevalence of $47.7 \%$ was found in Oshogbo, South Western Nigeria by Akanni et al and a comparable prevalence of $32 \%$ and $30.2 \%$ in Egypt and India respectively. ${ }^{16-18}$ These findings are however lower than the prevalence of $62 \%$ found in Ibadan, South West Nigeria as reported by Dawodu et al. ${ }^{19}$ These varying figures may be connected to the study population known to have different genetic composition and cultural practices. ${ }^{19,}{ }^{20}$ This is supported by the prevalence rates of G6PD deficiency among the Jews with a rate of $30 \%$ to $60 \%$ and the Arab Muslims with rates of $1.8 \%$ to $8.5 \%$ though living together for centuries in the same environment, suffering the same epidemics of malaria stressors but different cultures and religion. ${ }^{21}$ Many geneticists believe that the varying prevalence of G6PD deficiency population is a reflection of adaptation to malarial environments but frequency of carrier individuals, race, cultures, consanguineous and inter-ethnic marriages may have altered this adaptive response to malaria resulting in this unexpected variation within the same environment or region. ${ }^{21,22} \mathrm{~A}$ further study using a larger sample size will serve to confirm this finding. Methods of enzyme assay and sensitivity of these methods may have also significantly contributed to these variations. ${ }^{23,}{ }^{24}$ There is therefore the need to identify an acceptable, comparable, most sensitive and most specific assay method that will guarantee the authenticity of every report irrespective of where it is produced.

The sex distribution of G6PD deficient icteric neonates in this study showed a male proportion of $48.9 \%$ while the females were $27.5 \%$ with an approximate male: female ratio (M: F) of 3:1 similar to a finding in Iraq and some other parts of the World. ${ }^{25,26}$ This thus reaffirmed the natural history of G6PD deficiency being an X-linked recessive disorder, affecting male hemizygotes and female homozygotes or hemizygotes due to Turners' syndrome and if the phenomenon of normal $\mathrm{X}$-chromosome inactivation occurs. ${ }^{27} \mathrm{~A}$ statistically significant difference between G6PD deficient males and females was observed in this study. The mean level of G6PD activity depicted a lower activity in the deficient males due to reduced enzyme activity in all the males' red blood cell population. This also supports the fact that in heterozygote G6PD deficient females, half of their red blood cell populations have normal enzyme activity with the other halfexpressing deficient enzyme activity. ${ }^{28}$

In comparing the severity of hyperbilirubinaemia and G6PD levels, this study showed no statistically significant difference. This observation is comparable with that of Iolascum et al and Ainoon et al who stated that the level of enzyme activity in G6PD deficient erythrocytes does not bear a consistent relationship to degree of hyperbilirubinaemia. ${ }^{29}$

${ }^{30}$ It is however contrasting with a report from Iran where maximum total serum bilirubin levels were significantly higher among G6PD deficient icteric neonates when compared with G6PD normal icteric neonates. ${ }^{31}$ Contrary to the statistical conclusion on the relationship between hyperbilirubinaemia and G6PD status in this study, hyperbilirubinaemia of varying severity that requires urgent attention was demonstrated. Other factors may have influence the bilirubin levels in both groups and the fact still remains that attention must be given to any neonate with serum bilirubin levels of the magnitude demonstrated in this study irrespective of their G6PD status. The G6PD deficient icteric neonates in this study had normal haemoglobin concentration and haematocrit without changes suggestive of haemolysis. This therefore concurs with the view that the predominant factor in the pathogenesis of neonatal hyperbilirubinaemia associated with G6PD deficiency might 
be decreased bilirubin conjugation due to promoter polymorphism for the gene encoding the bilirubin conjugation enzyme resulting in decrease bilirubin elimination. ${ }^{32,33}$ This finding may also be related to the possible predominant G6PD variant in our environment which may not be the haemolysis causing variant. ${ }^{34}$

\section{CONCLUSION}

The high proportion of icteric neonates with G6PD deficiency in this study calls for a policy on early screening of all neonates through assessing their G6PD activity irrespective of their icteric status. This will assist in early detection of neonates with this deficiency and those at risk of developing hyperbilirubinaemia with the aim of instituting interventional measures to prevent its complications. There is also a need to carry out a larger population studies at National level to assay the G6PD activity in all neonates, identify the different G6PD variants and determine the national prevalence in our population.

\section{Acknowledgement}

Our appreciation goes to the entire work force of the Special Care Baby Units of the Jos University Teaching Hospital, Bingham University Teaching Hospital, and Plateau State Specialist Hospital. We are grateful to Mr. Pius of the Trust Care Laboratory for allowing us access to his Spectrophotometer

\section{Conflict of Interest}

None declared.

\section{REFERENCES}

1. Beutler E. Glucose-6-phosphate dehydrogenase deficiency: A historical perspective. Blood 2008; 111: 16-24.

2. Kaplan M, Hammerman C. Glucose-6-phosphate dehydrogenase deficiency: A Worldwide Potential Cause of Severe Neonatal Hyperbilirubinaemia. NeoReviews 2000; 1: 32-39.

3. Egesie OJ, Joseph DE, Isiguzoro I, Egesie UG. Glucose-6-phosphate dehydrogenase (G6PD) activity and deficiency in a population of Nigerian males resident in Jos. Niger J Physiol Sci 2008; 23: 9-11.

4. Ogunfowora OB, Daniel OJ. Neonatal jaundice and its management: Knowledge, Attitude, and Practice of Community health workers in Nigeria. BMC Public Health 2006; 6: 19-25.
5. Liaqat A, Liaqat A. Glucose-6-phosphate dehydrogenase deficiency in Jaundiced Neonates. J P M I 2010; 24: 122-126.

6. Dallol A, Banni H, Gari MA, Al-Qahtani MH, Abuzenadeh AM, Al-Sayes F, et al. Five novel Glucose-6-Phosphate Dehydrogenase Deficiency Haplotypes Correlating with Disease Severity. Journal of Translational Medicine 2012; 10: 199-207.

7. Azma RZ, Hidayata N, Farisah NR, Hanidah NH, Ainoon O. Glucose-6-phosphate dehydrogenase enzyme activity in normal term neonates and adults using OSMMR 2000-D kit with Hb-Normalization. Southeast Asian J Trop Med Public Health 2010; 41: 982-988.

8. Reclos GJ, Hatzidakis CJ, Schulpis KH. Glucose-6phosphate dehydrogenase deficiency neonatal screening: Preliminary evidence that a high percentage of partially deficient female neonates are missed during routine screening. J Med Screen 2000; 7: 46-53.

9. Uko EK, Agwunobi SN, Udoh JJ. Glucose-6phosphate dehydrogenase levels in jaundiced neonates in Calabar. Niger J Med 2003; 12: 98-102.

10. Obasa TO, Mokuolu OA, Ojuawo A. Glucose-6phosphate dehydrogenase levels in babies delivered at the University of Ilorin teaching hospital. Nig J Paediatr 2011; 38: 165-169.

11. George IO, Akani NA. Evaluation of Glucose-6phosphate dehydrogenase deficiency in icteric newborns in Nigeria. Am J Trop Med Pub Health 2011; 1: 73-78.

12. Simone C, Raquel W, Vivian D, Volnei T, Roberto G. Prevalence of G6PD deficiency in newborns in the South of Brazil. J Med Screen 2006; 13: 85-86.

13. Ademowo OG, Falusi AG. Molecular epidemiology and activity of erythrocyte G6PD variants in a homogenous Nigerian population. East Afr Med J 2002; 79: 42-44.

14. Ahmed H, Yakubu AM, Hendrickse RG. Neonatal Jaundice in Zaria, Nigeria: A Second Prospective Study. Ann Trop Paediatr 1995; 1: 15-23.

15. Amiwero CE, Olatunji PO. Prevalence of G6PD Deficiency in Children Presenting with Jaundice in Ilorin, Nigeria. Int J Biomed \&HlthSci 2012; 8: 21-26.

16. Akanni EO, Oseni BSA, Agbona VO, Tijani BA, Tosan E, Fakunle EE, et al. Glucose-6-phosphate dehydrogenase deficiency in blood donors and jaundiced neonates in Oshogbo, Nigeria. J Med Lab Diagn2010; 1: 1-4.

17. Amal AE, Nawal MK, Seham AA, Manal AF, Azza KA. Prevalence of Glucose-6-Phosphate Dehydrogenase Deficiency in Jaundiced Neonates in Egypt. Aust J of Basic and ApplSci 2009; 3: 20162023.

18. Pao M, Kulkarn A, Gupta V. Neonatal screening for G6PD Deficiency. Indian J Paediat 2005; 72: 835-837.

19. Dawodu AH, Owa JA, Familusi JB. A Prospective 
Study of the Role of Bacterial Infection and G6PD Deficiency in Severe Neonatal Jaundice in Nigeria. Trop Geogr Med 1984; 36: 127-132.

20. Rahim F, Zahid S, Mukhtiar SAS, Said H, Uzair M. Glucose-6-Phosphate Dehydrogenase Deficiency in Neonates Presenting with Jaundice. J Postgrad Med Inst 2008; 22: 102-106.

21. Cartwright-Jones C. Henna and the Evil Eye, Salt and Demons, and the Geography of G6PD Deficiency. PhD Thesis, Geography Department, Kent State University 2008: 1-20.

22. Howes ER, Battle KE, Satyagraha AW, Baird JK, Hay SI. G6PD Deficiency: Global Distribution, Genetic Variants, and Primaquine Therapy. Advances in Parasitology 2013; 81: 135-169.

23. Minucci A, Giardina B, Zuppi C, Capoluongo E. Glucose-6-phosphate Dehydrogenase Laboratory Assay: How, When, and Why? IUBMB Life 2009; 61: 27-34.

24. Wong FL, Boo NY, Ainoon O, Wang MK. Comparison of detection of Glucose-6-Phosphate Dehydrogenase Deficiency using fluorescent spot test, enzyme assay and molecular method for prediction of severe neonatal hyperbilirubinaemia. Singapore Med J 2009; 50: 62-67.

25. Al-Hiali SJ. Glucose-6-Phosphate Dehydrogenase Deficiency among Neonates with Hyperbilirubinaemia in Western Iraq. J Fac Med Baghdad 2008; 50: 431434.

26. Anwar ZJ, Shahzada BZ, Samreen Ahmad. Frequency of G6PD Deficiency and its Severity in Neonatal Jaundice in Rehman Medical Institute, Peshawar. Khyber Med Univ J 2013; 5: 36-39.

27. Moiz B, Nasir A, Khan SA, Kherani SA, Qadir M. Neonatal Hyperbilirubinaemia in infants with G6PD c.563C > T Variant. BMC Pediatrics 2012; 12: 126133.

28. Jarullah J, Aljaouni S, Sharma MC, Bushra MSJ, Kamal MA. Detection of Glucose-6- phosphate dehydrogenase deficiency in Heterozygous Saudi Female Neonates. EnzEng 2012; 1: 105-107.

29. Iolascum A, Faienza MF, Perrota S. Gilbert Syndrome and Jaundice In Glucose-6-Phosphate Dehydrogenase Deficient Neonates. Haematologica 1999; 84: 99-102.

30. Ainoon A, Alawiyah A, Yu YH, Cheong SK. Semi quantitative Screening Test for G6PD Deficiency: Detects Severe Deficiency but misses a Substantial Proportion of Partially-Deficient Females. South East Asian J Trop Med Public Health 2003; 34: 405-414.

31. Iranpour R, Hashemipour M, Talaei SM, Soroshnia M, Amini A. Newborn Screening for Glucose-6-Phosphate Dehydrogenase in Isfahan, Iran: a quantitative assay. J Med Screen 2008; 15: 62-64.

32. Kawade N, Onishi S. The prenatal and Postnatal Development of UDP-glucuronylTransferase Activity towards Bilirubin and The Effect of Premature Birth on this Activity in the Human Liver. Biochem J 1981; 196:
257-260.

33. Kaplan M, Levy-Lahad E, Hammerman C, Lahad A, Beutler E. Gilberts syndrome and Glucose-6-phosphate dehydrogenase deficiency: A dose-dependent genetic interaction crucial to neonatal hyperbilirubinaemia. ProctNatlAcadSci USA 1997; 94: 12128-12132.

34. Obasa TO, Adesiyun OO, Mokuolu OA, Ojuawo AI. Comparative analysis of Glucose-6-phosphate dehydrogenase levels in preterm and term babies delivered at University of Ilorin Teaching Hospital. Paediatric Reports 2012; 4: 21-24. 


\title{
Toxicity Study of Potash Extract, “jar Kanwa”: An Earthy Material Consumed for Remedy of various Ailments in Northern Nigeria
}

Rabiu $\mathrm{A}^{1^{*}}$ and Malami $\mathrm{S}^{2}$.

${ }^{1}$ Department of Obstetrics and Gynaecology, Bayero University Kano/Aminu Kano Teaching Hospital.

${ }^{2}$ Department of Pharmacology and Therapeutics, Bayero University Kano.

\begin{abstract}
Potash comprises potassium bearing minerals. These minerals are traditionally used for treatments of many ailments in Northern Nigeria with little knowledge of their safety profile. Acute toxicity (LD50) study of the potash extract was carried out on adults Wister rats. Based on the result of LD50; four groups of Wister rats; Group I, II, III and IV, each containing six males were formed. Group I was administered distilled water while group II was administered $20 \%$ $(1,000 \mathrm{mg} / \mathrm{kg})$ of the highest non-lethal dose. Group III and IV were administered 10\% (500 mg/kg) and 5\% (250 $\mathrm{mg} / \mathrm{kg}$ ) of the highest non-lethal dose respectively. These were done continuously for 28 days. Intakes of food and water were recorded daily while weights of animals were recorded weekly. There was no mortality at both phase $1 \& 2$ of the LD50. Results of chronic toxicity revealed two mortalities recorded in group II. Acute toxicity studies of potash extract showed that it is generally safe but in sub-chronic toxicity study, the extract was lethal on the experimental animals at higher doses. Therefore, consumption of this earthy material on a long term basis should be discouraged due to its lethal effects on animal studies
\end{abstract}

"Corresponding Author: Dr. Ayyuba Rabiu. Department of Obstetrics and Gynaecology, Bayero University Kano/Aminu Kano Teaching Hospital,P.M.B. 3011,E-mail: ayyubarabiu@yahoo.com,Phone No.08055559473

Keywords: Consumption, Potash Extract, Safety Profile, Wister Rats

\section{INTRODUCTION}

$\mathrm{P}$ otash is a broad term that covers all the bases when looking at potassium-bearing minerals. These minerals are naturally found in large evaporate deposits from ancient lake and sea beds or in rock formations. Literally potash means potassium compounds and potassium bearing materials. The word potash was derived in 1477 from the Middle Dutch word "potaschen" meaning pot ashes. ${ }^{2}$ Several health benefits of potash have been unraveled. It has been used for the treatment of cough, tooth ache relief, fungicidal, abortifacient and as a preservative. ${ }^{3}$ It is widely consumed by Nigerians, particularly those in the Northern part of the country with the belief that it suppresses sexual desire and provides some contraceptive properties. Conversely, potash poses health hazards on human beings, especially when consumed in a large quantity. Recent reports based on expert opinions believed that consumption of potash suppresses steroidogenesis and the high sodium content could also cause pathological changes to the liver and kidneys. ${ }^{4}$ There are different types of potash namely; sylvite ( $\mathrm{KCl}$, called regular potash or Muriate of potash), 
polyhalite or potassium sulfate $\left(\mathrm{K}_{2} \mathrm{SO}_{4}\right)$ /sulphate of potash, Carnallite (potassium magnesium chloride and water), Langbeinite (potassium magnesium) named sulfate of potash magnesia (SOPM), arcanite, arcanuni, salduplicatum, vitriolic tartar, Glaser's salt, Sal polychrestum Glaseri or potash of sulfur. ${ }^{1,3}$ Many types of mineral such as Polyhalite, Leonite, Kainite, Glaserite, Schönite, Langbeinite and potassium sulfate, can be separated from the potash. ${ }^{3}$

There is paucity of options and nomenclature of water soluble mineral salts especially by Hausas, of Northern Nigeria. Most evaporites including potash are called kanwa in Hausa language. The evaporites used in Northern Nigeria, locally called farar kanwa, jar kanwa, ungurnu are Tronas; Natron is classified as dutse dan Libya while manda is polyhalite.

In Nigeria, kanwa deposits are commonly found in northern part of the country, particularly in Kano, Maiduguri areas extending to border countries like Niger and Chad. ${ }^{6}$ It has varieties of uses such as food supplement and as a medicine. ${ }^{6}$ Farmers also use it as salt lick for animals in Northern Nigeria. Potash is referred to as kaun in Yoruba language and is commonly known as akanwu in Igbo language. ${ }^{8}$ All the three major Nigerian tribes (Hausa, Igbo and Yoruba) use potash in soups, legumes and meat mainly to faster tenderize tough cuts of meat and legumes, to colloid oil and water and to increase viscosity in some types of soups.

Research on the health benefits of potash is limited in the literature. However, understanding of its use in the world major fertilizer production firms, and inhalation of its dust by workers led to the investigation of the relationship between atmospheric dust levels and workers' health. Findings in relation to its effect where unremarkable. In an attempt to investigate the effects of potash consumption on kidneys, a study was conducted in southern Nigeria on Wistar rats. Findings from the study showed that at varying concentration of potash, there were progressive tubular and vascular changes, cellular necrosis and glomerular degeneration and these imply that potash is cytotoxic to the kidney tissues of wistar rats. They concluded that excessive consumption of this earthy material may lead to its accumulation that could cause severe and irreparable damage to the kidneys and disrupt normal body functions. ${ }^{10}$ This research was aimed at determining the toxicity of potash extract among male wistar rats.

\section{MATERIALS AND METHODS}

This research was conducted in the Pharmacology laboratory of Bayero University Kano from $1^{\text {st }}$ June, 2018 to $31^{\text {st }}$
October, 2018. A pure potash extract was collected from Haji Bukaran, an area of Nguru Local Government area of Yobe State. The collected pure sample of potash was grinded to a powdered state using pestle and mortar. Three kelograms of powdered potash was dissolved in 2 liters of distilled water. The solvent was filtered using No 1 Whatmann's filter paper, size 12.5 micron and allowed to dry in desiccators at $45^{\circ} \mathrm{C}$. The process was repeated until adequate potash extract was obtained.

Adults Wistar rats were purchased from the Animal House of Ahmadu Bello University (ABU) Zaria with a weight of 110$130 \mathrm{~g}$ each. The rats were kept at the animal house of Pharmacology department of Bayero University Kano (BUK) under normal laboratory conditions. They were allowed unrestricted access to standard feed (Vital feed growers) obtainable from Grand Cereals and Oil Mills Ltd, Bukuru, Jos, Nigeria and water ad libitum throughout the experimental period. They were handled in accordance with the guidelines for the care and use of laboratory animals. The animals were randomly selected and marked to allow individual identification and kept in their cages for five days prior to the experiment to allow for acclimatization to the laboratory conditions.

Acute toxicity (LD50) study of the potash was carried out using the method described by Lorke. ${ }^{11}$

This method entertained two phases as follows:

Phase 1: This phase required nine Wistar rats which were divided into three groups of three animals each. Each group was administered different doses $(10,100$ and $1000 \mathrm{mg} / \mathrm{kg}$ ) of the potash solution. The rats were fasted for 18 hours prior to dosing. The potash solutions were administered to the rats once orally using 22-gauze oral feeding needle based on their weights. The Wistar rats were then placed under observation for 24 hours to monitor their behavior as well as if mortality would occur.

Phase 2: This phase involved the use of three wistar rats, which were distributed into three groups of one animal each. These wistar rats were administered higher doses $(1600,2900$ and $5000 \mathrm{mg} / \mathrm{kg}$ ) of potash extract solution and then observed for 24 hours for behavior as well as mortality.

Then the $\mathrm{LD}_{50}$ was calculated by the formula:

$\mathrm{D}_{0}=$ Highest dose that gave no mortality,

$\mathrm{D}_{100}=$ Lowest dose that produced mortality.

Based on the result of LD50; four groups of wistar rats; Group I, II, III and IV, each containing six males were formed. 
Group I were administered distilled water while group II were administered $20 \%$ of the highest non-lethal dose. Group III and IV were administered $10 \%$ and $5 \%$ of the highest nonlethal dose respectively. These were done continuously for 28 days. Intakes of food and water were recorded daily while weights of animals were recorded weekly. Approval for the study was obtained from the ethical committee of Bayero University Kano (BUK /CHS/ REC/ VI/ 56), after due consideration of animal health and the advancement of knowledge on humans or animals weighed against the potential impacts on the welfare of the animals. Following the approval, the researcher was under obligation to ensure that laboratory animals were treated according to high ethical and scientific standards.

\section{RESULTS}

Results of $\mathrm{LD}_{50}$ showed no mortality at both phase $1 \& 2$. Table 1. Therefore, the maximum dose of $5,000 \mathrm{mg} / \mathrm{kg}$ was found to be non-lethal to the wistar rats. In the results of chronic toxicity, Group II, III and IV of the wistar rats were given $1,000 \mathrm{mg} / \mathrm{kg}, 500 \mathrm{mg} / \mathrm{kg}$ and $250 \mathrm{mg} / \mathrm{kg}$ of potash extract daily over a period of 28 days while group 1 (control) was on food and water only (Table 2) There were no significant changes in weight of the wistar rats, intake of food and water during the period of the study. There were two mortalities recorded in group II. Figure 1 and 2 depict the crude potash (jar kanwa) and the extract respectively.

Table 1: Acute Toxicity Study

\begin{tabular}{lllll}
\hline Groups & Number of Wistar rats & Dose (mg/kg) & Period under observation (Hours) & Mortality/behavioral changes \\
\hline Phase 1 & & 10 & 24 & Nil \\
Group I & 3 & 100 & 24 & Nil \\
Group II & 3 & 1,000 & 24 & Nil \\
Group III & 3 & & & Nil \\
Total & $\mathbf{9}$ & & & Nil \\
\hline Phase 2 & & 1,600 & 24 & Nil \\
Group I & 1 & 24 & \\
Group II & 1 & 2,900 & 24 & \\
Group III & 1 & 5,000 & & \\
Total & $\mathbf{3}$ & & & \\
\hline
\end{tabular}

Table 2: Chronic Toxicity Study

\begin{tabular}{|c|c|c|c|c|c|}
\hline Groups & $\begin{array}{l}\text { Number of } \\
\text { Wistar rats } \\
\end{array}$ & Dose (mg/kg) & $\begin{array}{l}\text { Percentage of highest } \\
\text { non- lethal dose }(\%)\end{array}$ & $\begin{array}{l}\begin{array}{l}\text { Duration } \\
\text { (days) }\end{array} \\
\end{array}$ & $\begin{array}{l}\text { Mortality/ } \\
\text { behavioral change }\end{array}$ \\
\hline I (control) & 6 & 0 & 0 & 28 & nil \\
\hline II & 6 & 1,000 & 20 & 28 & 2 Mortalities \\
\hline III & 6 & 5000 & 10 & 28 & nil \\
\hline IV & 6 & 250 & 5 & 28 & nil \\
\hline
\end{tabular}

Note: Highest non lethal dose based on acute toxicity study was 5,000 $\mathrm{mg} / \mathrm{kg}$

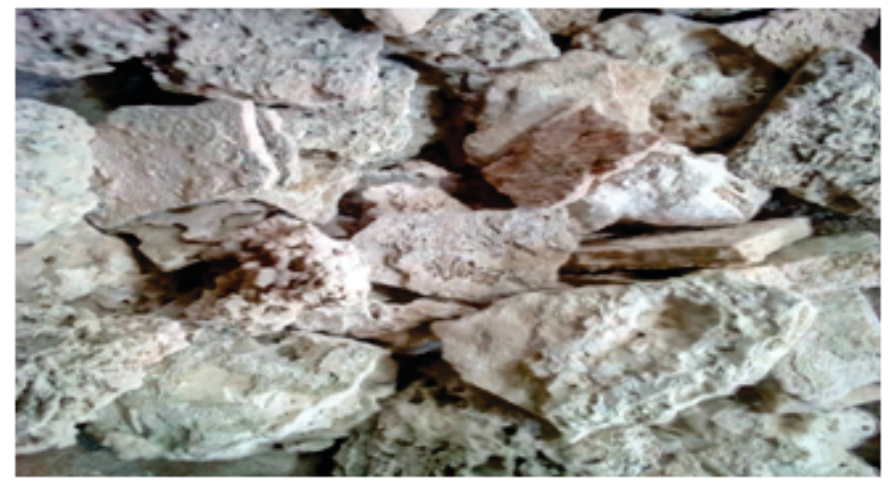

Figure 1: Samples of Potash

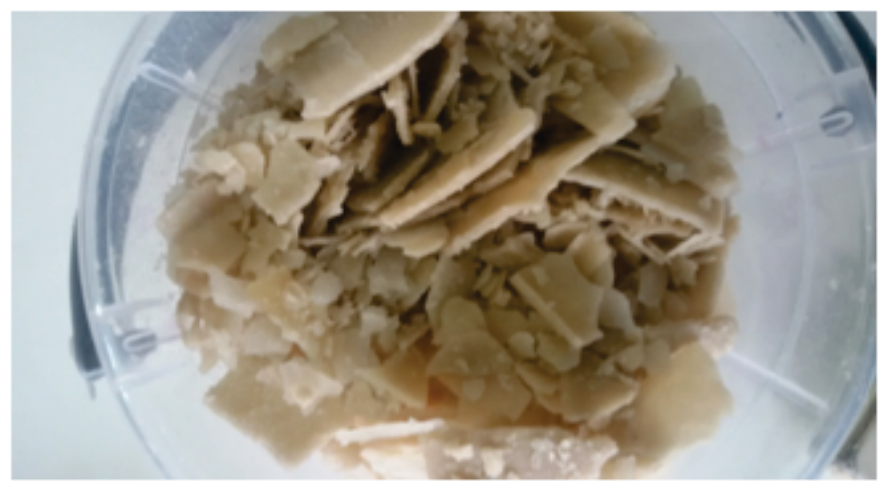

Figure 2: Extract of the Potash 


\section{DISCUSSION}

The result of lethal dose 50 , the dose that kills $50 \%$ of test animals' population (wistar rats) when exposed to potash extract showed no mortality. This was similar to the findings of Imafidon and Omoregie $\mathrm{e}^{12}$ on toxicological and biochemical investigations in rats administered "kaun" (trona), a natural food additive used in Nigeria. Iweka and colleagues ${ }^{13}$ in South-Southern Nigeria in a study on the effect of potash on liver function of wistar rats also reported no mortality on acute toxicity study following potash treatment. This shows that the potash is safe when consumes on short term basis but on long term use, it is lethal for we recorded two mortalities in the 28 day period of exposure. Furthermore, the mortality was recorded in the $1,000 \mathrm{mg} / \mathrm{kg}$ group, i.e., the group with highest dose ( $20 \%$ of the non lethal dose).

A toxicological and biochemical investigations in rats administered trona, a naturally occurring inorganic substances (salts), used mainly as food additive showed that no demonstrable significant toxic effects. And its administration to rats up to $5000 \mathrm{mg} / \mathrm{kg}$ resulted in no mortality of the test rats after 24 hours. Hence the $\mathrm{LD}_{50}$ of this potash extract was estimated to be greater than $5000 \mathrm{mg} / \mathrm{kg}$ as they also found in trona. ${ }^{14}$ The $\mathrm{LD}_{50}$ was not calculated in this study because there was no mortality at $5000 \mathrm{mg} / \mathrm{kg}$ dose level indicating that it is relatively safe under short term exposure. However, acute toxicity data are of limited clinical application since cumulative toxic effects especially at a dose of $1,000 \mathrm{mg} / \mathrm{kg}$ was found to be lethal due to the recording of two mortalities. Based on the findings of a study conducted on the effects of chronic exposure to lead, cadmium, and manganese mixtures on oxidative stress in rat liver and heart, it was concluded that exposure to these heavy metals could result in distribution and accumulation of these metals in the body and subsequent weakening of the immune system ${ }^{15}$ which could eventually lead to mortality as was noticed in this study.

\section{CONCLUSION}

Acute toxicity studies of potash extract showed that it is generally safe but in sub-chronic toxicity study, the extract was lethal on the experimental animals at higher doses. As part of our recommendation, we discourage consumption of these earthy materials on a long term basis due to its lethal effects on animal studies.

\section{Limitation}

We could not do pathological assessment of the wistar rats after chronic exposure of the potash extract.

\section{Acknowledgement}

Special thanks to the management of Bayero University, college of Health Sciences and the Department of Pharmacology, BUK, Kano.

\section{Conflict of Interest}

None declared.

\section{REFERENCES}

1. Diniz V. Potash Investing; Four Kinds of Potash [Internet]. 2013 [cited 2018 Mar 22]. Available from: https://investingnews.com/daily/resourceinvesting/agriculture-investing/potash-investing/fourkinds-of-potash/

2. van der Sijs N. Potash (Scheikundig Element) [Internet]. etymologiebank.nl. 2010. Available from: http://etymologiebank.nl/trefwoord/potas

3. Okpala B. Benefits of Kaun Potash (Akanwu) [Internet]. Blog. 2018. Available from: https://globalfoodbook.com/benefits-of-kaun-potashakanwu

4. Anonymous. Excessive consumption of potash reduces sperm production - Expert [Internet]. 2016. Available from: http://dailypost.ng/2016/04/06/excessiveconsumption-of-potash-reduces-sperm-productionexpert/

5. Abdulhamid Z. Ethnomedical survey and biological studies of some evaporites (Kanwa) used in Hausa and Fulani traditional medicine in some selected Local Government Area in Kaduna State, Nigeria. 2016.

6. Omajali J, Momoh S. Effects of Kanwa on gastrointestinal phosphatase. Int J Pharm Sci Nanotechnol. 2010;3(2):1147-52.

7. Lovejoy P. A History of Salt Production and Trade in the Central Sudan. York University, Toronto; 1986.

8. Anonymous. Potash (Kaun) Can Cause Abortions [Internet]. 2018 [cited 2018 Mar 22]. Available from: https://www.mamalette.com/blog/pregnancy/pleasenote-consuming-potash-kaun-can-induce-abortionsearly-stages-pregnancy/

9. Markham JW, Tan LK. Concentrations and health effects of potash dust. Am Ind Hyg Assoc J [Internet]. 1981;42(9):671-4. Available from: https://www.ncbi.nlm.nih.gov/pubmed/7293929

10. Bankole JK, Ngokere AA, Ajibade OM, Igunbor CM, Eloka CCV. Degenerating effects of potash (KaunK2co3) on the kidney: Unabated continental challenge to human health in Nigeria. Ann Biol Res [Internet]. 2015;6(3):12-8. Available from: http://scholarsresearchlibrary.com/archive.html

11. Lorke D. A new approach to practical acute toxicity testing. Arch Toxicol [Internet]. 1983;54(4):275-87. Available from: https://www.ncbi.nlm.nih.gov/pubmed/6667118

12. KE, Imafidon, Omoregie I. Toxicological and biochemical investigations in rats administered "kaun" 
(trona), a natural food additive used in Nigeria. J Nutr Intermed Metab. 2016;6:22-5.

13. Iweka FK, Dic-Ijiewere OE, Oaikhena F, Bankole JK, Festus OO, Dada F. The Effect of Potash on Liver Function of wistar Rats. Int J Herbs Pharmacol Res. 2016;5(1):13-20.

14. Ima K, Egberanmwen I, Omoregie I. Journal of Nutrition \& Intermediary Metabolism Toxicological and biochemical investigations in rats administered " kaun " ( trona ) a natural food additive used in Nigeria. J Nutr Intermed Metab. 2016;6:22-5.

15. Markiewicz-górka I, Januszewska L, Michalak A, Prokopowicz A, Pawlas N, Pawlas K. Effects of chronic exposure to lead , cadmium, and manganese mixtures on oxidative stress in rat liver and heart. Arh Hig Rada Toksikol. 2015;66:51-62. 


\title{
Knowledge of Healthcare Workers on Immunization: New and Under- utilized and Perception towards Future Vaccines
}

\author{
Jibo $\mathrm{AM}^{1^{*}}$ Karaye $\mathrm{RS}^{2}$, Gajida $\mathrm{AU}^{1}$, Abulfathi $\mathrm{AA}^{3}$ \\ ${ }^{I}$ Department of Community Medicine, Bayero University Kano \\ ${ }^{2}$ Department of Pediatrics, Murtala Mohammed Specialist Hospital, Kano \\ ${ }^{3}$ Department of Community Medicine, Aminu Kano Teaching Hospital, Kano
}

\author{
*Corresponding Author: Dr A.M. Jibo. Department of Community Medicine, Bayero University Kano, Kano, Nigeria \\ Email: ajmohammed.cmed@buk.edu.ng.
}

\begin{abstract}
Nigeria is making effort to address the child mortality burden by increasing vaccine coverage rates, yet the vaccine coverage falls short of $90 \%$ target. Scaling up of new and under-used vaccines to $90 \%$ coverage could save more than 600,000 Nigerian children. Healthcare givers knowledge of vaccine used for immunization is essential to increase the vaccine uptake rates. This study assesses the knowledge of routine, underutilized and future vaccines among health workers. A cross sectional descriptive study was done among health care workers at a tertiary health facility in Nigeria. Using a pre-tested semi structured interviewer administered questionnaire, 220 respondents were selected by cluster sampling technique. The health workers' knowledge of these vaccines was assessed using a scale developed for the study. Data collected were analyzed using SPSS version 22. The mean age of the respondents was $31.9 \pm 5.7$ years . Doctors and nurses formed more than half of the respondents, $51.8 \%(\mathrm{n}=114)$. About three quarters of respondents $72.3 \%(n=159)$ had good knowledge of vaccines used in routine immunizations. Knowledge of under-utilized and future vaccine was low with less than a fifth $18.6 \%(n=41)$ and one tenth $9.1 \%(n=20)$ having good knowledge scores respectively. Similarly, poor perception scores of future vaccines were observed in $90.1 \%(n=218)$ of the respondents. Only marital status was associated with knowledge of underutilized vaccines $(\mathrm{p}<0.05)$ and no association was observed between other sociodemographic variables and knowledge of these vaccines $(\mathrm{P}>0.05)$. The awareness level of health care workers on routine immunization is high. Their knowledge and perception of under-utilized and future vaccines were however low. There is, therefore, need for more training and retraining of health care workers on the vaccines.
\end{abstract}

Keywords: Health worker, Knowledge, Under-utilized, Vaccines

\section{INTRODUCTION}

$\mathrm{O}$ ne of the most important ways to improve immunization services is to have parents and health care workers that work towards the benefits of immunization to the growing child. The purpose of the immunization program is to achieve high coverage among children so as to reduce morbidity and mortality that results from vaccine preventable diseases. 'Although the benefit of preventing suffering and death from serious infectious diseases greatly outweighs the rare adverse effect following immunization, ${ }^{2}$ disputes have arisen over the morality, ethics, cost, effectiveness and safety of 
vaccination. ${ }^{2}$ Some vaccination critics say that vaccines are ineffective against disease, or that vaccines safety studies are inadequate. ${ }^{3}$ Some religious groups do not allow vaccination and some political groups oppose mandatory vaccination on the grounds of individual liberty. ${ }^{4,5}$ In the first decade of $21 \mathrm{st}$ century, religious and political leaders with some health care workers $(\mathrm{HCW})$ in northern Nigeria, suspicious of western medicine advised their followers not to have their children vaccinated with oral polio vaccine (OPV). The immunization was suspended for several months. Subsequently, Nigeria reported over 200,000 measles, polio and other vaccine preventable disease (VPD) cases and about 600 deaths from measles in the first quarter of $2008 .^{6}$

Studies have shown that parents and healthcare workers play an essential role in playing improving the number of children reached and ensuring they are fully covered with antigens appropriate for their age. ${ }^{7,8}$ Lack of adequate knowledge on immunization could be a major cause of decline of the vaccine coverage rate, thus training of providers has been found to improve immunization uptake elsewhere. ${ }^{8}$ In a review of evidence on how health care workers determine uptake of immunization it was found that suboptimal vaccination rates resulted from inadequate knowledge among healthcare providers of vaccination schedules, as well as the benefits and side effects. ${ }^{9}$ In some cases, healthcare providers were even found to have misleading beliefs about immunisation and sent unclear or untrue messages to parents. ${ }^{9}$ Nigeria has taken important steps in recent years to address the child mortality burden by increasing vaccine coverage yet, the vaccine coverage fall short of $90 \%$ target, ${ }^{10}$ Scaling up of new and under-used vaccines to $90 \%$ coverage could save more than 600,000 Nigerian children from VPD in the next ten years, and eventually add an economic value equivalent to $\$ 17$ billion to the nation's economy. ${ }^{11,12}$ The study was done at a tertiary health facility in Kano. The state has an estimated maternal mortality ratio of 1600 per 100,000 live births, an under-five mortality of 157 deaths per 1000 births in 2008 . About $13 \%$ of deliveries in the state were attended to by a skilled birth attendant and only $11 \%$ of these deliveries take place in a health care facility. Furthermore, only $6 \%$ of the population receives required vaccination and more than half of the children have not received their immunization. We therefore, assessed the knowledge of routine and underutilized vaccine among $\mathrm{HCW}$ and their perception on future vaccines and how it relates to immunization services in the country.

\section{MATERIALS AND METHODS}

The study was a hospital based cross sectional descriptive study. Kano state has a total of 44 local government areas, and eight of them are metropolitan. The 2018 projected population of the state is 11,401,847 (based on the 2006 National Population Census), with an almost equal distribution of male (51\%) and female (49\%). The health system is organized at three levels namely: primary, secondary and tertiary levels. There are three tertiary health institutions sited in the metropolis; Murtala Mohammed Specialist Hospital, Mohammed Abdullahi Wase Specialist Hospital and Aminu Kano Teaching Hospital. There are an estimated 161 private health facilities distributed across the state. Aminu Kano Teaching Hospital (AKTH) was established on 24th of August 1988. The facility is located along Zaria road in Tarauni Local government area in Kano metropolis. It is a five hundred beds hospital that provides specialized services to patients from Kano and neighbouring states, as well as West Africa countries. The hospital has about 17 departments, 15 wards, laboratory complexes and specialty clinics. The hospital has a staff strength of 2,600 comprising of both administrative and clinical staff. Apart from medical services, the hospital also provides training for medical students, interns, resident doctors and mid-level healthcare workers.

Our study population were health care staff working at health facilities offering immunization in services. The Leslie Fishers formula was used to calculate the minimum size for this study. A total of 220 respondents were selected by cluster sampling technique after meeting up the inclusion criteria. A semi-structured interviewer administered questionnaire was developed and pre-tested for the study. The questionnaire captures information on the socio-demography of the respondents, knowledge of health care workers on routine immunization, new and under-utilized vaccines as well as the perception of the health workers toward future vaccine. The knowledge of routine, underutilized and future vaccine was assessed based on a scoring system developed for the study. Each positive response has one mark score and a zero score for a wrong response. The maximum score obtainable was 21 for assessment of knowledge of routine vaccines (score of 0 10 considered as poor knowledge, and scores of 11-21 was considered good knowledge). Similarly, the maximum score obtainable for assessment of knowledge of underutilized vaccines was 52-point scale (score of 0-26 graded as poor 
knowledge, and scores of 27-52 was considered good knowledge). Assessing the knowledge of future vaccines was a 7-point scale with scores of 0-3 considered as poor knowledge and scores of 4-7 good knowledge score. Perception towards future vaccine was analyzed using Likert's scale and also graded as good on a scale of 11- 20 score and poor perception if it is between 0-10 score. The maximum score on the perception scale was 20 points. Data were entered manually into a spreadsheet on Microsoft excel and analyzed using SPSS Version 22. Quantitative data were summarized using mean, standard deviation, while Qualitative data were presented using frequency tables. Tests of associations between categorical data was performed, Chisquare test of association was used to test for statistically significant associations. A P-value of 0.05 or less was considered significant.

Ethical approval for this study was obtained from ethical committee of Aminu Kano Teaching Hospital and Kano State Hospital Management Board ethical committee. All respondents were made to sign consent before participating and assurances were given on confidentiality of data collected.

\section{RESULTS}

Of the 220 respondents that participated, $124(56.36 \%)$ were males, and 96(43.64\%) were females. The mean age of the respondents was 31.9 with a standard deviation of 5.7 years. All the respondents were drawn from a tertiary health facility.

Table 1: Sociodemographic characteristics of the respondents

\begin{tabular}{lll}
\hline $\begin{array}{l}\text { Socio demographic } \\
\text { features }\end{array}$ & $\begin{array}{l}\text { Frequency } \\
\text { N=220 }\end{array}$ & Percentage \\
\hline Age groups (years) & 10 & \\
$15-24$ & 146 & 4.6 \\
$25-34$ & 56 & 66.4 \\
$35-44$ & 8 & 25.5 \\
$45-54$ & 124 & 3.6 \\
Sex & 96 & 56.4 \\
Male & & 43.6 \\
Female & 128 & \\
Ethnic group & 32 & 58.2 \\
Hausa & 29 & 14.6 \\
Igbo & 31 & 13.3 \\
Yoruba & & 14.1 \\
others & 76 & 34.5 \\
Marital Status & 143 & 65.0 \\
single & 1 & 0.5 \\
married & & \\
widowed & 60 & 27.3 \\
Professional Qualification & 54 & 24.5 \\
Doctor & 53 & 24.1 \\
Nurse & 26 & 5.5 \\
CHEW & 12 & 6.8 \\
Lab Scientist & 15 & 47.3 \\
Technician & & 31.8 \\
Others & 104 & 17.7 \\
Years of Service & 70 & \\
Less than 5 & 39 & \\
5-10 & 7 & \\
11 -15 & & \\
16-20 & &
\end{tabular}

Table 2: Knowledge of routine immunization vaccines

\begin{tabular}{lll}
\hline Knowledge Assessed (n=220) & $\begin{array}{l}\text { Correct knowledge } \\
\text { F (\%) }\end{array}$ & $\begin{array}{l}\text { Incorrect knowledge } \\
\text { F (\%) }\end{array}$ \\
\hline Ever heard of routine Immunization vaccines & $220(100.0)$ & $0(0.0)$ \\
Facility offers vaccine for Immunization & $220(100.0)$ & $0(0.0)$ \\
Knows RI vaccine Schedule & $173(78.6)$ & $47(21.4)$ \\
Knows appropriate vaccine for age & $175(79.5)$ & $45(20.5)$ \\
Knows Vaccine preventable diseases & $218(99.1)$ & $2(0.9)$ \\
Knows when to start child Immunization & $220(100.0)$ & $0(0.0)$ \\
Knows Adverse events following Immunization & $131(59.5)$ & $89(40.5)$ \\
Knows Contraindications to Immunization & $115(52.3)$ & $105(47.7)$ \\
\hline
\end{tabular}

Table 3: Knowledge of Underutilized Vaccine among HCW

\begin{tabular}{|c|c|c|}
\hline Knowledge Assessed $(\mathrm{n}=220)$ & $\begin{array}{l}\text { Correct Knowledge } \\
\text { Freq }(\%)\end{array}$ & $\begin{array}{l}\text { In Correct Knowledge } \\
\text { Freq }(\%)\end{array}$ \\
\hline Aware of Underutilized vaccines & $119(54.1)$ & $101(45.9)$ \\
\hline \multicolumn{3}{|l|}{ Vaccines Identified as Under Utilized } \\
\hline Pneumococcal conjugate vaccine & $62(28.2)$ & $158(71.8)$ \\
\hline Typhoid Vaccine & $57(25.9)$ & $163(74.1)$ \\
\hline Influenza vaccine & $48(21.8)$ & $172(78.2)$ \\
\hline Hepatitis A vaccine & $42(19.1)$ & $178(80.9)$ \\
\hline Hepatitis B vaccine & $77(35.0)$ & $143(65.0)$ \\
\hline Yellow fever vaccine & $30(13.6)$ & $190(86.4)$ \\
\hline Rubella & $23(10.5)$ & $197(89.6)$ \\
\hline Rotavirus vaccine & $23(10.5)$ & $197(89.6)$ \\
\hline Cholera Vaccine & $40(18.1)$ & $180(81.8)$ \\
\hline Meningococcal conjugate vaccine & $69(31.4)$ & $151(68.6)$ \\
\hline Hemophilus Influenza type b vaccine & $58(26.4)$ & $162(73.6)$ \\
\hline Human papilloma Virus Vaccine & $75(34.1)$ & $145(65.9)$ \\
\hline \multicolumn{3}{|l|}{ Pneumococcal Vaccine } \\
\hline Knows target population & $75(65.9)$ & $145(34.1)$ \\
\hline Knows disease conditions it protects & $59(26.8)$ & $161(73.2)$ \\
\hline Knows number of doses required for protection & $2(0.9)$ & $218(99.1)$ \\
\hline Knows availability & $47(21.4)$ & $173(78.6)$ \\
\hline \multicolumn{3}{|l|}{ Typhoid Vaccine } \\
\hline Knows target population & $6(2.7)$ & $214(97.3)$ \\
\hline Knows disease conditions it protects & $54(24.4)$ & $166(75.5)$ \\
\hline Knows number of doses required for protection & $3(1.4)$ & $217(98.6)$ \\
\hline Knows availability & $28(12.7)$ & $192(87.3)$ \\
\hline \multicolumn{3}{|l|}{ Influenza Vaccine } \\
\hline Knows target population & $44(20.0)$ & $176(80.0)$ \\
\hline Knows disease conditions it protects & $50(22.7)$ & $170(77.3)$ \\
\hline Knows number of doses required for protection & $5(2.3)$ & $215(97.7)$ \\
\hline Knows availability & $45(20.5)$ & $175(79.5)$ \\
\hline \multicolumn{3}{|l|}{ Hepatitis A Vaccine } \\
\hline Knows target population & $80(36.4)$ & $140(63.6)$ \\
\hline Knows disease conditions it protects & $76(34.5)$ & $144(65.5)$ \\
\hline Knows number of doses required for protection & $10(4.5)$ & $210(95.5)$ \\
\hline Knows availability & $40(18.2)$ & $180(81.8)$ \\
\hline \multicolumn{3}{|l|}{ Hepatitis B Vaccine } \\
\hline Knows target population & $110(50.0)$ & $110(50.0)$ \\
\hline Knows disease conditions it protects & $105(47.7)$ & $115(52.3)$ \\
\hline Knows number of doses required for protection & $60(27.3)$ & $160(72.7)$ \\
\hline Knows availability & $95(43.2)$ & $125(56.8)$ \\
\hline \multicolumn{3}{|l|}{ Rota virus Vaccine } \\
\hline Knows target population & $26(11.8)$ & $194(88.2)$ \\
\hline Knows disease conditions it protects & $39(17.7)$ & $181(82.3)$ \\
\hline Knows number of doses required for protection & $7(3.2)$ & $213(96.8)$ \\
\hline Knows availability & $7(3.2)$ & $173(96.8)$ \\
\hline \multicolumn{3}{|l|}{ Cholera Vaccine } \\
\hline Knows target population & $77(35.0)$ & $143(65.1)$ \\
\hline Knows disease conditions it protects & $76(34.5)$ & $144(65.5)$ \\
\hline Knows number of doses required for protection & $13(5.9)$ & $218(94.1)$ \\
\hline Knows availability & 30 (13.6) & $190(86.4)$ \\
\hline \multicolumn{3}{|l|}{ Meningococcal Vaccine } \\
\hline Knows target population & $32(14.5)$ & $188(85.5)$ \\
\hline Knows disease conditions it protects & $84(38.2)$ & $136(61.8)$ \\
\hline Knows number of doses required for protection & $7(3.2)$ & $203(96.8)$ \\
\hline Knows availability & $63(28.6)$ & $157(71.4)$ \\
\hline \multicolumn{3}{|l|}{ Hib Vaccine } \\
\hline Knows target population & $67(30.5)$ & $153(69.5)$ \\
\hline Knows disease conditions it protects & $56(25.5)$ & $164(74.6)$ \\
\hline Knows number of doses required for protection & $13(5.9)$ & $207(94.1)$ \\
\hline Knows availability & $43(19.6)$ & $177(80.4)$ \\
\hline \multicolumn{3}{|l|}{ HPV Vaccine } \\
\hline Knows target population & $76(34.6)$ & $144(65.4)$ \\
\hline Knows disease conditions it protects & $85(38.6)$ & $135(61.4)$ \\
\hline Knows number of doses required for protection & $11(5.0)$ & $209(95.0)$ \\
\hline Knows availability & $43(19.6)$ & $177(80.5)$ \\
\hline
\end{tabular}


All the healthcare workers studied are aware of vaccines used in routine immunization and know when a child should start receiving vaccines. More than half of the respondents 131 (59.5) were able to mention at least three adverse events that could follow immunization in a child.

The respondents were assessed on underutilized vaccine. The responses are shown in table 2 above.

Table 4: Perception of Future Vaccines Amongst Health care workers

\begin{tabular}{|c|c|c|c|}
\hline Perception & $\begin{array}{l}\text { Incorrect } \\
F(\%)\end{array}$ & $\begin{array}{l}\text { Correct } \\
\mathrm{F}(\%) \\
\end{array}$ & $\begin{array}{l}\text { Undecided } \\
\text { F (\%) }\end{array}$ \\
\hline \multicolumn{4}{|l|}{ When planning to introduce new vaccine we consider: } \\
\hline Vaccine efficacy & $220(100.0)$ & & \\
\hline Vaccine effectiveness & $218(99.9)$ & $0(0)$ & $2(0.1)$ \\
\hline Severity of disease & $209(95.0)$ & $7(3.2)$ & $4(1.8)$ \\
\hline Burden of disease & $206(93.6)$ & $12(5.5)$ & $2(0.9)$ \\
\hline Risk to contacts & $202(91.8)$ & $16(6.8)$ & $3(1.4)$ \\
\hline Public concerns & $193(87.7)$ & $25(11.4)$ & $2(0.1)$ \\
\hline Coverage & $211(95.9)$ & $6(2.7)$ & $3(1.4)$ \\
\hline \multicolumn{4}{|l|}{ When introducing a vaccine in to community consider: } \\
\hline Supply issues & $216(98.2)$ & $4(1.8)$ & - \\
\hline logistics associated with the new vaccine. & $208(94.6)$ & $10(4.5)$ & $2(0.9)$ \\
\hline economic and financial issues & $211(95.9)$ & $8(3.6)$ & $1(0.4)$ \\
\hline \multicolumn{4}{|l|}{ Introducing a new vaccine means you have to: } \\
\hline Revise the practice guidelines & $163(74.1)$ & $48(21.8)$ & $9(4.1)$ \\
\hline Revise of Road-to-Health charts & $151(68.6)$ & $59(26.8)$ & $10(4.6)$ \\
\hline Training of health workers & $169(76.8)$ & $51(23.2)$ & \\
\hline Cold chain Logistics and Manuals, & $189(85.9)$ & $25(11.4)$ & $6(2.7)$ \\
\hline Information, Education and Communication for the public & $207(94.1)$ & $12(5.5)$ & $1(0.4)$ \\
\hline Monitoring of Adverse Events & $210(95.5)$ & $8(3.6)$ & $2(0.9)$ \\
\hline Surveillance of the disease in question. & $204(92.7)$ & $12(5.5)$ & $4(1.8)$ \\
\hline You can monitor the success of a new vaccine by: & & & \\
\hline Estimating the burden of the disease, & $205(93.2)$ & $12(5.5)$ & $3(1.4)$ \\
\hline Determining the Effectiveness of the vaccine, & $211(95.9)$ & $8(3.6)$ & $1(0.4)$ \\
\hline Determining the Coverage achieved & $213(96.8)$ & $7(3.2)$ & \\
\hline
\end{tabular}

Table 5: Knowledge and Perception of the respondent on Vaccines

\begin{tabular}{lll}
\hline Assessment & \multicolumn{2}{l}{ Frequency Percentage } \\
\hline Knowledge of Routine Vaccine & & \\
Good (score 11-21) & 159 & 72.3 \\
$\begin{array}{l}\text { Poor (score 0-10) } \\
\text { Knowledge of Underutilized vaccine }\end{array}$ & 61 & \\
Good (score 27-52) & & \\
Poor (score 0-26) & 41 & 18.6 \\
& 179 & 81.4 \\
Knowledge of Future Vaccines & & \\
Good (score 4-7) & 20 & 9.1 \\
Poor (score 0-3) & 200 & 90.9 \\
\hline Perception of FutureVaccines & & \\
Good Perception (score 11-20) & 2 & 0.9 \\
Poor Perception (score 0-10) & 218 & 90.1 \\
\hline
\end{tabular}

Fewer respondents have been observed to have good perception $0.9 \%(n=20)$, knowledge of future $9.1 \%(\mathrm{n}=20)$ and underutilized vaccines $18.6 \%(\mathrm{n}=41)$ from the study.
Table 6: Relationship between Sociodemographic features and Knowledge of Vaccines

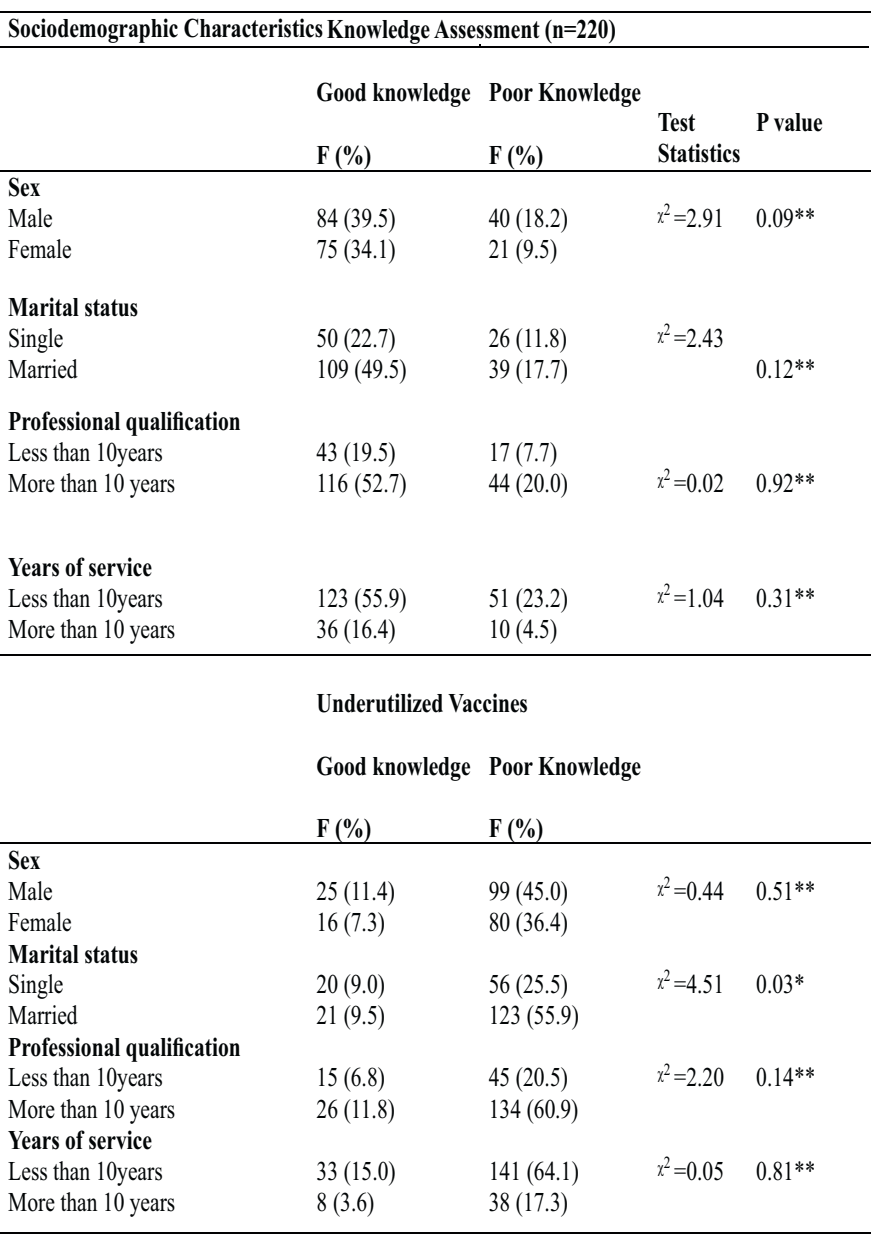

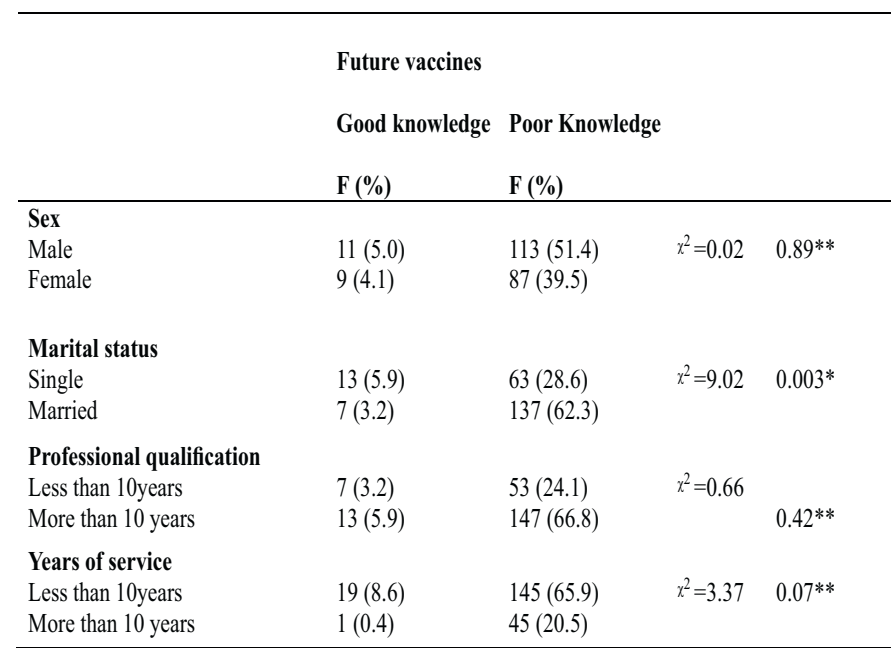

\section{DISCUSSION}

Good knowledge of vaccines used in routine immunizations was observed among the respondents, however knowledge of underutilized as well as future vaccine was poor. Awareness of routine immunization was high similar to what was 
reported by other studies, ${ }^{12,13}$ however differs from findings here because caregivers were used as study population in these studies. Inadequate parental knowledge and information and that of healthcare workers could grossly affect the uptake and utilization of childhood immunization as reported by many studies. ${ }^{14,15}$, If the main problem among healthcare providers is lack of knowledge, in most cases, suboptimal vaccination rates result from this inadequate knowledge and will affect vaccination schedules and benefits.Vaccines against hepatitis B, Hemophilus influenza type b, yellow fever, rubella, typhoid and cholera have been widely available in industrialized countries for years, but are underutilized effectively in developing countries. New formulations or combination vaccines that decrease the number of injections, overcome vaccine wastage, and improve actual and perceived adverse event profile of the vaccines are available. Our study demonstrated poor knowledge of future and underutilized vaccines. Where the healthcare worker does not have adequate information on the vaccines used, it will undoubtedly affect uptake, coverage and utilization. Healthcare providers ranked first among most used and most trusted sources of information on vaccines as reported from studies in western Europe. ${ }^{17-19}$

Healthcare workers routinely provide information about recommended vaccinations to their patients and informed them about benefits and risks. When the healthcare providers sounded vague, some parents may interpret this as concern that the vaccine was unsafe. ${ }^{20}$ Furthermore, if healthcare workers' knowledge was found to be inadequate, vaccination coverage in the general population may decrease. The same happens when healthcare workers were reported to have a relaxed attitude towards immunization, which is itself a consequence of lack of knowledge and may lead to more problems. ${ }^{9}$ We observed a very low perception to future vaccines. This differs to what was reported from Netherland, ${ }^{21}$ where $43 \%$ of the respondents were reported to have positive perception and attitudes towards all vaccinations including the new vaccines. Perhaps because the caregivers were used as the respondents in Netherland study. An extensive range of vaccines are in the development pipeline against many diseases of public health importance. Only marital status was found to be positively associated with Knowledge of vaccines $(p<0.05)$. Contrary to what was reported by other studies where years of service and professional qualification plays a major role in the knowledge of health worker.

\section{CONCLUSION}

Healthcare workers were found to have a high knowledge of routine immunization vaccine but poor knowledge of future and underutilized vaccine. The perception of future vaccine was also observed to be low. The need to have training and more information on future and underutilized vaccine will go a long way in improving the utilization of some of these new and utilized vaccines in our community.

\section{Recommendation}

It is recommended from this study that healthcare workers that work in immunization units of our health facilities should have regular training and skills updates to enable them tackle the challenges of immunization in Nigeria. This will improve uptake, utilization and coverage of immunization services among the population.

\section{Limitation}

Our study has been limited by the fact that the health workers were drawn from the same facility but their selection followed a clearly laid down scientific procedure to eliminate any form of bias.

\section{Acknowledgement}

We acknowledge the cooperation given to us by the Kano state Ministry of Health Research board, the head of the tertiary facility used as well as the healthcare workers that participated in this study.

\section{Conflict of Interest}

None declared.

\section{REFERENCES}

1. Bolanle B. V, Abimbola O.O, Olusola M.:Impact of training intervention on immunization providers' knowledge and practice of routine immunization in Ibadan, south-western Nigeria: a primary health care experience Pan African Medical Journal. 2017;26: 216. doi:10.11604/pamj.2017.26.216.11545

2. Sinal SH, Cabinum-Foeller E, Socolar R. Religion And Medical Neglect. Southern Medical Journal2008;101(7):703-706

3. Halvorsen R, The truth about vaccines. The Brit J of Gen Pract2007;57:(542):679-757

4. Demichili V, Jefferson T, RivettiA, Price D. Vaccines For Measles Mumps and Rubella In Children. Pub med journal ;2005:19(4)

5. Basin H. The Ethics Of vaccine Usage In the Society; 
Lessons from the past. Pub med Journal; 2001:25(30):104-108

6. Clement CJ, Green nough P, Shull D. How Vaccine Policy Can become political- The example of polio in Nigeria: Current Drug Safety journal 2006: 1(1):117119

7. Al-lela OQ, Bahari MB, Salih MR, Al-Abbassi MG, Elkalmi RM, Jamshed SQ. Factors underlying inadequate parents' awareness regarding pediatrics immunization: findings of cross-sectional study in Mosul- Iraq. BMC Pediatr. 2014; 14: 29.

8. Anastasi D, Di Giuseppe G, Marinelli P, Angelillo IF. Paediatricians knowledge, attitudes, and practices regarding immunizations for infants in Italy. BMC Public Health. 2009; 9: 463.

9. Simone B, Carrillo-Santisteve P, Lopalco PL. Healthcare workers' role in keeping MMR vaccination uptake high in Europe: a review of evidence. Euro Surveill. 2012;17(26):pii=20206. Available online: http://www.eurosurveillance.org/ViewArticle.aspx? Articleld $=20206$

10. Endurance A. Ophori, Musa Y. Tula ,Azuka V. Azih, Rachel Okojie and Precious E. Ikpo. Review of Current Trends of Immunization in Nigeria: Prospect and Challenges. Tropical Medicine and Health. 2014;. 42 .(2), , 67-75 doi: 10.2149/tmh.2013-13

11. NPHCDA: Routine Immunization Strategic plan in Nigeria 2013-2015. Available on http://www.nationalplanningcycles.org/sites/default Lfiles/country docs/Nigeria/ri strategic plan combi ned mahmud draft 1.pdf. Date accessed??

12. Deady J. Thornlon L. Parent's knowledge of and attitude towards the primary childhood immunizations. Ireland Med Journal. 2005 ; 98 (1): 7 - 8

13. Kabir M, Ilyasu Z, Abubakar I.S Gajida A.U. knowledge perception and beliefs of mothers on routine childhood immunization in a northern Nigerian village. Annals of Nigerian medicine2005; 1 , . (1) 21-26

14. Kabir M, Abubakar I.S Iliyasu Z. and Nwosuh J.I Immunization coverage in children below 2 years of age in Fanshekara Kano State Nigeria. Journal of basic and clinical sciences, 2004;1 .(1):, $10-13$.

15. Hamlin $\mathrm{J}$, et al: Inappropriately timed immunizations: types, causes, and their relationship to record keeping. Am J Public Health 1996,86(12):1812-1814.

16. Hariweni $\mathrm{T}$, et al: Knowledge, attitude, and practice of underfive children stimulation of working and nonworking mothers. PaediatrIndones 2004,44(3-4):101-105

17. Attitudes Knowledge and practice of health professionals regarding immunization. Australian and New Zealand journal of public health.2008: ???...224225

18. Pantha S, Pragya GS. Knowledge awareness and practices of Hepatitis A and $B$ vaccination among medical students of Chittagong medical college. European journal of hepato-gastro enterology; 2011:1(1):23-25
19. Cotter S, Ryan F, Hegarty H, McCabe TJ, Keane E. Immunisation: the views of parents and health professionals in Ireland. Euro Surveillance. 2003; 8(6). Available from: http://www.eurosurveillance.org/ViewArticle.aspx?Arti cleId=416 .[Accessed 5th July 2012].

20. Hilton S, Petticrew M, Hunt K. Parents' champions vs. vested interests: who do parents believe about MMR? A qualitative study. BMC Public Health. 2007;7:42.

21. Hak, E, Schonbeck,Y, De Melker H, Van EssenGA. Negative attitude of highly educated parents and health care workers towards future vaccination in the Dutch childhood vaccination program. Elsevier Journal; 2005:23(24)3103-3107 


\title{
Invasive Sino-Orbital Aspergillosis in an Immunocompetent Patient
}

\author{
Okolo $\mathrm{OM}^{1}$, Bot $\mathrm{GM}^{2}$, Onyedibe $\mathrm{IK}^{1}$, Shilong $\mathrm{DJ}^{2}$, Alfin $\mathrm{DJ}^{2}$, Adoga $\mathrm{AS}^{3}$, Dahal AS${ }^{1}$, Ogbe $\mathrm{ME}^{4}$, Egah $\mathrm{ZD}^{1}$, Binitie $\mathrm{OP}^{2}$.
}

${ }^{1}$ Department of Medical Microbiology, ${ }^{2}$ Division of Neurosurgery, Department of Surgery, ${ }^{3}$ Department of Ear Nose and Throat (ENT), and ${ }^{4}$ Department of Anaesthesia, College of Health Science, University of Jos, Nigeria.

*Corresponding Author: Okolo Mark Ojogba. Department of Medical Microbiology, University of Jos, Plateau State, Nigeria. Email: okolomark@gmail.com

\begin{abstract}
Invasive aspergillosis that involves intra-orbital and intracranial extension occurs in immunodeficient and immunocompetent patients resulting in significant morbidity and mortality. We report the case of a 38year old farmer who had recurrent fronto-ethmoidal mucocoele and proptosis of the left eye. She presented with a history of hypertension and no other significant findings on examination. Computer tomography scan of the brain showed a left fronto-orbital uniform contrast-enhancing extra-axial lesion with thickened peripheral capsule and an associated left fronto-orbital skull defect. Cerebrospinal fluid analysis did not show any sign of infection. Intra-operative biopsy sample showed cheesy material which on culture grew Aspergillus species that was identified further using molecular methods. Antifungal agents were used to treat the patient. The present case strongly suggests that it is possible to control intracranial aspergillosis with a combination of surgery and antifungal chemotherapy.
\end{abstract}

\section{Keywords: Invasive aspergillosis, Aspergillus,Immunocompetent, Fungal infection}

\section{INTRODUCTION}

spergillosis of the paranasal sinuses and orbit
usually is self-limiting with a good prognosis. In
contrast, invasive diseases may result in significant
morbidity and mortality from intra-orbital and
intracranial extension. Invasive disease occurs in
debilitated patients with decreased immunity such as
diabetes mellitus, Human Immunodeficiency Virus,
cytotoxic drugs users, etc. ${ }^{1.3}$ Intracranial extension often
results in mortality despite therapy. Nonetheless,
invasive sino-orbital aspergillosis may occur in
immunocompetent patients resulting in significant
morbidity and mortality. The standard treatment for
invasive sino-orbital diseases has been radical surgical intervention, including orbital exenteration, sinus excision, and aggressive intracranial debridement. However more recently, poor prognosis have been reported with a combination of limited surgical debridement and anti-fungal therapy particularly in immunocompetent patients due to late presentation to health care facility. We present a case of invasive sinoorbital aspergillosis with extension into the dura complicated by cheesy collection in an immunocompetent patient. The patient was successfully managed with surgical debridement and anti-fungal chemotherapy.

\section{Case report: history and examination}

A 38 year old female who had gross total resection of 
fronto-orbital lesion, with intracranial extension for about 3 years prior to presentation. However, she started having serous discharge from the operation site about one year after the surgery with associated proptosis of the left eye. There was no discharge from the nose, ear or contralateral eye. Her medical history included only hypertension. The patient had marked proptosis, limitation of extra ocular motility, ptosis, and a large discharging (left) supra orbital sinus. The patient is immunocompetent as revealed by nonreactive retroviral screening test. The other findings from the physical examination were not significant. The patient was admitted and reviewed by both Neurosurgery and the Otorynolaryngology team, and a computer tomography scan of the brain was performed prior to surgery.

\section{Hospital care}

The imaging study of the patient's brain showed a left frontoorbital uniformly contrast-enhancing extra-axial lesion with thickened peripheral capsule. (fig1a,1b,1c) There was an associated left fronto-orbital skull defect and thickening of the left maxillary sinus mucosa and calcifications.

A thorough medical examination and review of patient, including Human Immunodeficiency Virus screening, did not reveal evidence of immunodeficiency disorder or systemic fungal infection. Given the immunocompetence of the patient, chronic nature of the disease, clinical and radiologic findings, a diagnosis of Recurrent fronto-ethmoidal mucocoele with fistula was made and the patient was prepared for external frontoethmoidectomy. Intraoperatively, a left fronto-cutaneous fistula was seen, cheesy material with frontal sinus with extension to the dura as well as reactive dura was observed. The cheesy material was evacuated and sent to the laboratory, irrigation was carried out and haemostasis secured with electrocautery. A frontonasal stent was placed for two weeks to allow for epithelization and enhanced drainage from the frontal sinus to the nasal cavity to allow for healing of the fronto-cutaneous fistula.

\section{Microbiology and molecular examination}

Cultures of the cheesy material sample obtained were consistent with Aspergillus species (figure 2). Internal transcribed spacer (ITS) region gene sequencing was performed to reliably identify the organism. The universal primers for fungi $\mathrm{F}$ (5'-TCCGTAGGTGAACCTGCGG-3') and R(5'-TCCTCCGCTTATTGATATGC-3') was used and generating a sequence which on BLAST analysis matched Aspergillus aculeatus (GenBank accession number MN187974.1) was identified. Due to unavailability of antifungal drugs, patient was commenced empirically on intravenous fluconazole for two weeks and discharged home on oral voriconazole $(300 \mathrm{mg})$ twice daily. The patient is eight months post-surgery doing very great.

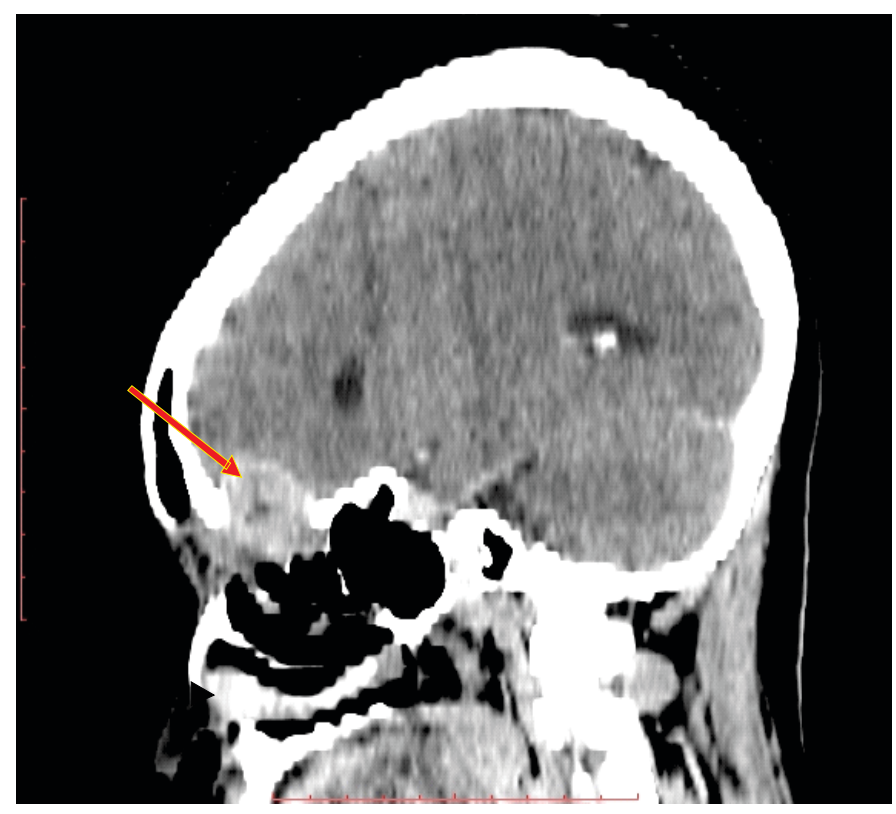

Fig 1a: Brain computer tomography scan showing lesion (arrow) in the fronto-nasal sinus.

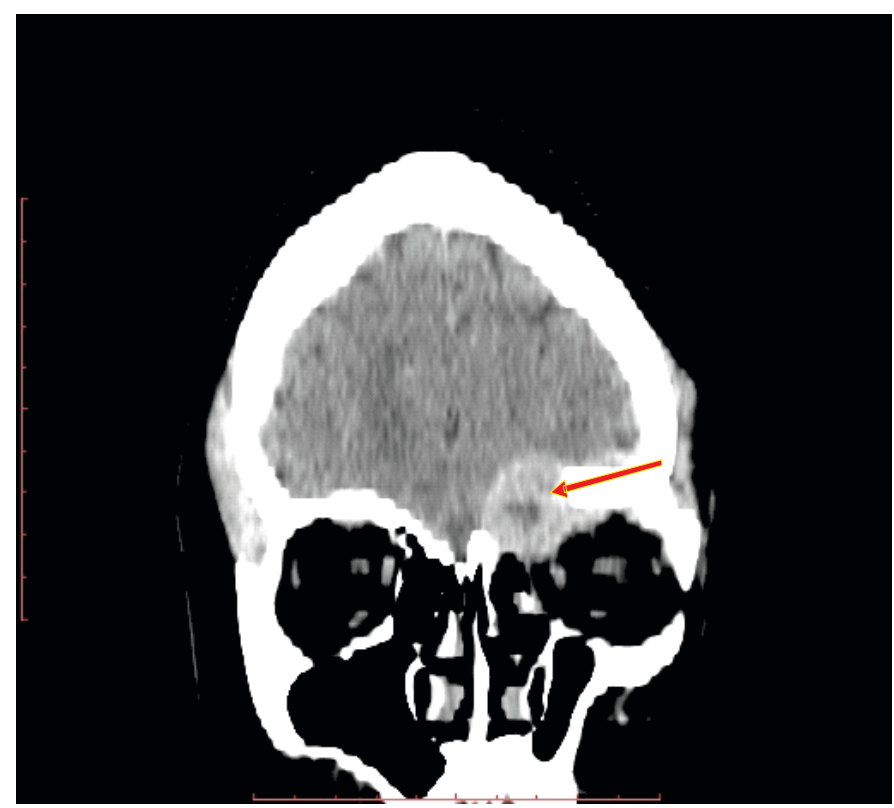

Fig 1b: Computer tomography scan of the brain showing(arrow) a left fronto-orbital uniform contrast-enhancing extra-axial lesion. 